\title{
WestVirginiaUniversity
}

THE RESEARCH REPOSITORY @ WVU

Graduate Theses, Dissertations, and Problem Reports

2005

\section{Personality factors and other predictors of academic success in medical students}

\author{
T. Anne Hawkins \\ West Virginia University
}

Follow this and additional works at: https://researchrepository.wvu.edu/etd

\section{Recommended Citation}

Hawkins, T. Anne, "Personality factors and other predictors of academic success in medical students" (2005). Graduate Theses, Dissertations, and Problem Reports. 2240.

https://researchrepository.wvu.edu/etd/2240

This Dissertation is protected by copyright and/or related rights. It has been brought to you by the The Research Repository @ WVU with permission from the rights-holder(s). You are free to use this Dissertation in any way that is permitted by the copyright and related rights legislation that applies to your use. For other uses you must obtain permission from the rights-holder(s) directly, unless additional rights are indicated by a Creative Commons license in the record and/ or on the work itself. This Dissertation has been accepted for inclusion in WVU Graduate Theses, Dissertations, and Problem Reports collection by an authorized administrator of The Research Repository @ WVU.

For more information, please contact researchrepository@mail.wvu.edu. 


\title{
Personality Factors and Other Predictors of Academic Success in Medical Students
}

\author{
T. Anne Hawkins, MA.
}

\author{
Dissertation submitted to the \\ College of Human Resources and Education \\ at West Virginia University \\ in partial fulfillment of the requirements \\ for the degree of
}

Doctor of Philosophy

in

Counseling Psychology

\author{
Margaret K. Glenn, Ed.D., Chair \\ Bob Marinelli, Ed.D. \\ Scott Meit, PsyD. \\ Richard T. Walls, Ph.D. \\ Roy Tunick, Ph.D. \\ Department of Counseling, Rehabilitation Counseling, \\ and Counseling Psychology \\ Morgantown, West Virginia \\ 2005
}

Keywords: retention, attrition personality trait, predictors, medical students Copyright 2005 T. Anne Hawkins 


\section{Abstract \\ Personality Factors and Other Predictors of Academic Success in Medical Students T. Anne Hawkins}

This study examines the relationship between objectively derived personality characteristics of West Virginia University medical students and their rate of retention and attrition in medical school. Personality trait characteristics are assessed using the 16 Personality Factor Questionnaire (16PF, $5^{\text {th }}$ edition). Relationships between student reported race, gender, age, undergraduate cumulative grade point average, undergraduate cumulative science grade point average, Medical School Admission Test scores, and retention and attrition rates were also examined. Graduation status and academic quartile ranking were used to measure outcome. Chi-Square and ANOVA procedures were used to test the research hypotheses. 


\section{DEDICATION}

For my partner, Mary and my son, Ben, who with their love and support make everything possible. 


\section{ACKNOWLEDGEMENTS}

The errors in this work are all mine but the final draft and all that is scholarly and noteworthy in the pages that follow would not exist without the support of many individuals. First, the chair of my committee, Margaret Glenn Ph.D, who made me believe that I could actually do this work and who at the end of this process, encouraged my autonomy and "brought me down from the ceiling." Next to acknowledge is my committee: Dick Walls Ph.D.; Bob Marinelli, Ed.D., Roy Tunick, Ed.D; and, most especially, Scott Meit, Psy.D., ABPP and Nicole Borges, Ph.D who provided thoughtful and constructive support. I am grateful for all the time and energy they devoted to making me a better writer and scholar.

This research would not have been possible without the support of Scott Meit Psy.D, who generously shared a critical data set and sat with me for hours as we talked about research possibilities and my development as a psychotherapist. The WVU School of Medicine (Ann Cather, MD, Norman Ferrari, MD and Pam Carico) opened doors (and files) for me, which enabled the development of the retention dataset which was used in this study.

Finally, I would like to acknowledge the women who have mentored and supported me through-out my life (without them I would not have had the courage or confidence to embark upon this journey):

Mrs. Cutlip one of my junior high school teachers, who matter of factly said to me, "of course you're going to go to college .... "You'll be a doctor or a lawyer someday" and I believed her.

Linda K., the women of SisterSpace and the WVU Women Studies Center who opened their doors and their lives to me and taught me about community and the power of women.

Mary Jane, who by example, taught me about integrity, justice and jumping off into the unknown.

$\mathrm{MB}$, who taught me about life and the value of living well with the people whom I love and who has tirelessly read and witnessed my "work" and transformative journey.

Rosemary, who has always been in the room with me supporting my activism, my partnering and parenting, and who said to me " Of course, you're going to be a therapist and get a PhD" and left me little choice.

Sherry, who inspires me with her gentleness, her scholarly work, devotion to mentoring and her commitment to living well. 
Britt, Sam, Tandy and most recently, Jen who through this process (the life-long one) have believed in, supported (laughed at) and sustained me.

Mary, who selflessly put her "life and needs" on hold and who never questioned (at least not out loud!) why we committed to this process and who, in her commitment to medical students, inspired mine 


\section{TABLE OF CONTENTS}

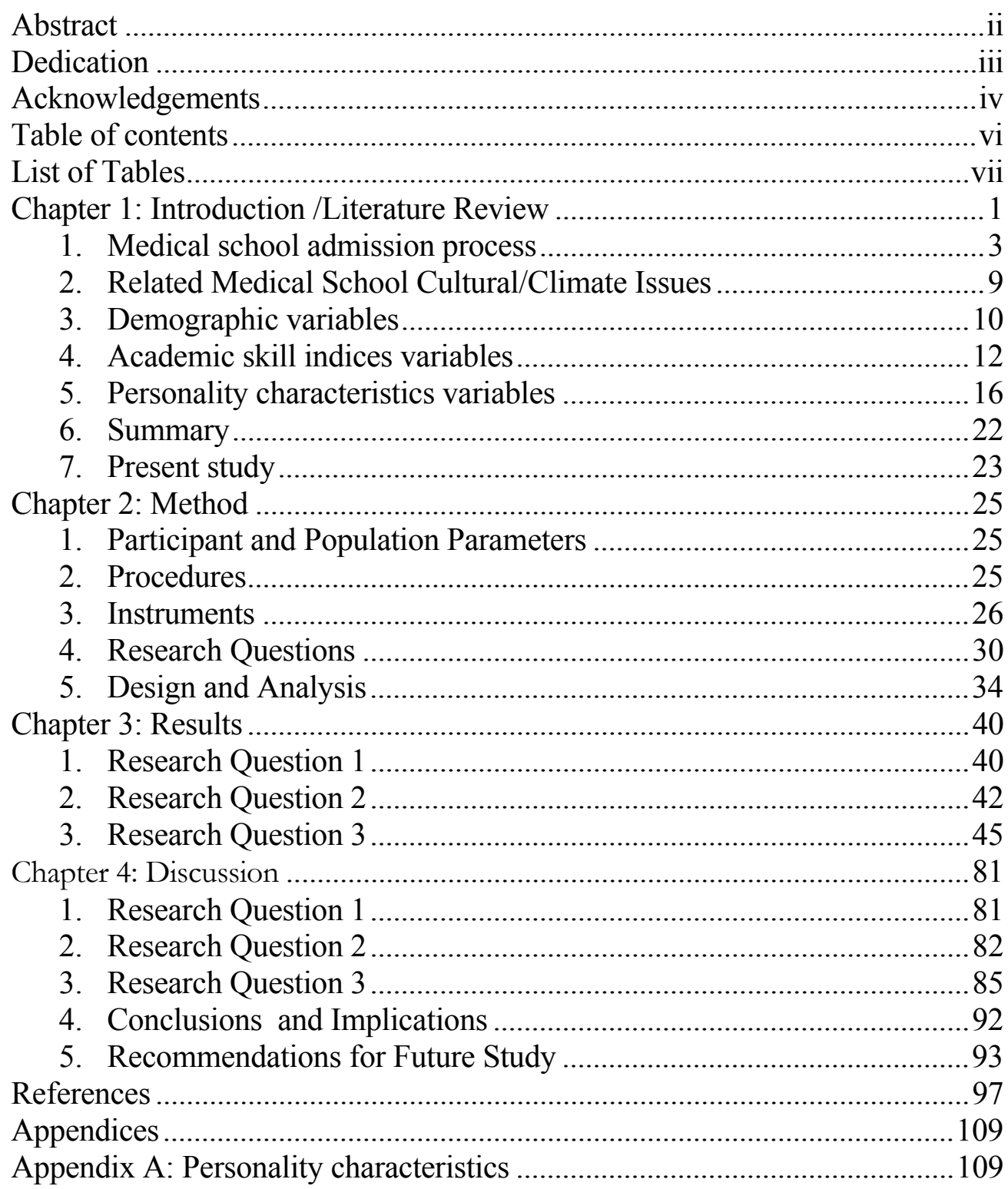


List of Tables

Table 1. Independent and Dependant Variables, Design of the Research ..............38

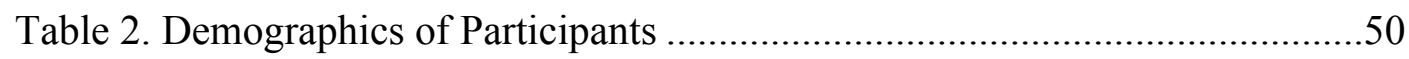

Table 3. Research Hypothesis 1.1 Sex Frequencies and Chi-Square ...................51

Table 4. Research Hypothesis 1.2 Race Frequencies and Chi-Square Results .......52

Table 5. Research Hypothesis 1.3 Age Frequencies and Chi-Square ....................53

Table 6. Research Hypothesis 2.1 CGPA.........................................................54

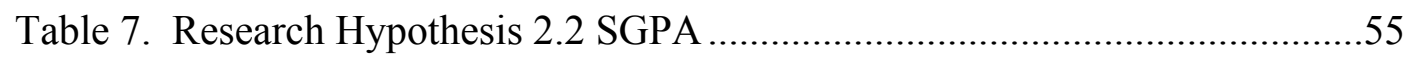

Table 8. Research Hypothesis 2.3 MCAT Score...............................................56

Table 9. Research Hypothesis 2.3 MCAT Biosciences

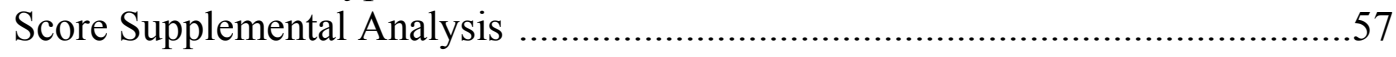

Table 10. Research Hypothesis 3.1 Extraversion................................................58

Table 11. Research Hypothesis 3.2 Anxiety ..................................................59

Table 12. Research Hypothesis 3.3 Tough-Mindedness ...................................60

Table 13. Research Hypothesis 3.4 Independence .........................................61

Table 14. Research Hypothesis 3.5 Self-Control ...........................................62

Table 15. Research Hypothesis 3.6 Warmth ...............................................63

Table 16. Research Hypothesis 3.6 Reasoning ...............................................64

Table 17. Research Hypothesis 3.6 Emotional Stability ..................................65

Table 18. Research Hypothesis 3.6 Dominance ...............................................66

Table 19. Research Hypothesis 3.6 Liveliness .............................................67

Table 20. Research Hypothesis 3.6 Role Consciousness .................................68

Table 21. Research Hypothesis 3.6 Social Boldness........................................69

Table 22. Research Hypothesis 3.6 Sensitivity ........................................... 70 
Table 23. Research Hypothesis 3.6 Vigilance Means, .......................................71

Table 24. Research Hypothesis 3.6 Abstractness ................................................ 72

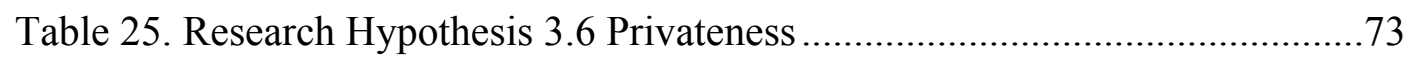

Table 26. Research Hypothesis 3.6 Apprehension Means, ................................73

Table 27. Research Hypothesis 3.6 Openness to Change ....................................75

Table 28. Research Hypothesis 3.6 Self-Reliance ..........................................76

Table 29. Research Hypothesis 3.6 Perfectionism ........................................... 77

Table 30. Research Hypothesis 3.6 Tension Means, ........................................... 78

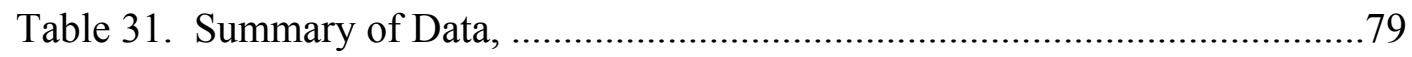




\section{CHAPTER 1}

\section{INTRODUCTION/LITERATURE REVIEW}

The purpose of this research is to begin to identify characteristics common to medical students who are successful in their course of study. This research can serve to assist both students and medical institution faculty members as they address retention issues and the rising costs associated with medical education.

Understanding the nature of the variables which correlate with academic success in a medical school environment, and how they potentially interact, is a difficult undertaking. What is it that distinguishes students who succeed from those who struggle, and from those who cannot or do not successfully navigate the medical education process? Do some students arrive on campus with a higher cognitive skill baseline? Do they inherently possess or have they developed different personality characteristics than their less successful counterparts? Over the years, a number of studies have attempted to identify academic indice variables which correlate with success in medical school environments. Studies investigating the relationship between Medical School Admission Test (MCAT) scores, cumulative undergraduate grade point average (CGPA), undergraduate science grade point average (SGPA), and personal characteristics of medical students (race, gender, etc.), have frequently been used to predict successful medical school matriculation (Cariaga-Lo, Enarson, Crandall, Zaccaro, \& Richards, 1997; Tekian, Mrtek, Syftestad, Foley, \& Sandlow, 1996). High MCAT scores, CGPA, SGPA have frequently been associated with higher graduation rates (Cariaga-Lo et al., 1997; Claap \& Reid, 1976; Green, Peters, \& Webster, 1993; Jones \& Adams, 1983; Sarnacki, 1982). 
Other studies examining the relationship between personality traits and academic success report positive relationships between various medical student personality characteristics and their relationship to mental health, coping skills, residency choice, and academic success (Borges \& Savickas, 2002; Cariaga-Lo et al., 1997; Tyysen \& Vaglum, 2002; Tyysen, Vaglum, Gronvold, \& Ekenberg, 2001; Shen \& Comrey, 1997). The personality traits that were found to be associated in the literature with academic success in medical school include: honesty, confidentiality, mental toughness, warm heartedness, respect for others and the law, empathy, perseverance, tolerance for ambiguity, compulsiveness, perseverance, aggressiveness, and encouraging behavior (Lievens, Coetsier, De-Fruyt, \& De Maeseneer, 2002, Nath, 1987; Robbins, Robbins, Katz Gelibeter, \& Stern, 1983; Shen \& Comrey). Much debate continues to exist regarding which personality traits correlate with academic success (Hojat, Robeson, Damjanov, Veloski, Glaser, \& Gonella; 1993; Shen \& Comrey, 1997). This debate continues largely because of the difficulty in drawing generalizable conclusions across studies that have used a wide variety of personality assessment instruments (Lievens et al., 2002).

Understanding how these cognitive and personality variables interact, and their relationship to retention and academic success, has long been an important issue for medical schools (American Medical Association [AMA], 2003). In many medical schools, $10-15 \%$ of the members of an entering cohort do not graduate with their peers (Daugherty, Eckenfels, \& Schmidt, 1990). Students may drop out, stop out, be dismissed, or require additional time to complete the program requirements. Medical students lost through attrition represent a potential loss of talent and expertise for the medical profession and ultimately impact delivery of patient care. Medical schools also 
experience the impact of attrition in the form of lost revenue. Soaring tuition, fees, and related expenditures have pushed the average cost of a medical degree up to $\$ 103,855$ in 2003 (AMA, 2003). A better understanding of the characteristics that correlate with success in medical school may decrease these losses for both medical schools and their respective students.

This study attempts to determine if specific personality characteristics as measured by the 16 Personality Factors Questionnaire, $5^{\text {th }}$ edition, and undergraduate CGPA, SGPA, and MCAT scores, may be correlated with success (or lack thereof) in medical school. Secondary to this effort will be a review of the correlations between medical student demographics (gender, age, and race) and academic success in medical school.

\section{Literature Review}

This section begins with a discussion of the medical school admissions process and is followed by a review of the literature regarding predictors of success in medical education, including: demographic variables, academic skill indices, and personality characteristics. This section concludes with a synopsis of this research and a rationale for the selection of the 16 PF Questionnaire, $5^{\text {th }}$ edition, for use in the proposed research study.

\section{Medical School Admission Process}

Medical schools in the United States generally follow a standardized process of admission. The components of this process are described in this subsection and include: The American Medical College Application Service (AMCAS), MCAT, and applicant CGPA and SGPA. 
In $2003,34,786$ prospective medical students applied to 126 medical schools in the United States with a national acceptance rate of 30\% (American Medical Education Association, 2003). A longitudinal review of the applicant pool suggested that applications by females have increased by $20 \%$ and for minorities by $45 \%$ from 1974 to 1999 (Hall, Mikesell, Cranston, Julian, \& Elam, 2001). The national ratio of male to female applicants for the 2001 medical class was reportedly, $52.5 \%$ to $47.5 \%$ (Association of American Medical Colleges, 2002). For the first time, the number of female applicants exceeded male applicants in class of 2002 (Association of American Medical Colleges, 2003). Although the number of female applicants to the school of medicine used in this study for the class of 2002 did not exceed male applicants (female applicants $48 \%$, a $4 \%$ increase of female applicants was observed from the previous year. (B. Dlugos, personal communication, April, 15, 2004).

During 2003, the following changes were reported in the national medical school applicant pool: $6.1 \%$ decline in white applicants, 9.1\% decline in Asian/Pacific Islander applicants, and a $4.5 \%$ decline in underrepresented minority groups (Association of American Medical Colleges, 2003). Similar changes in the WVU applicant pool during the same time frame were not evident (B. Dlugos, personal communication, April, 15, 2004).

Medical admission processes begin in the fall of each academic year. Admission decisions are based upon multiple criteria determined by the faculty of respective medical schools (Edwards, Johnson, \& Molidor, 1990; Kulatunga-Moruzi \& Norman, 2002b). These criteria are often related to the institution's mission and goals. Generally, medical schools attempt to admit students who can demonstrate that they possess the intellectual 
and personal qualities desired in physicians, as well as the characteristics required to persevere in, and ultimately complete, the rigorous medical school curriculum (AMA, 2003; Edwards et al., 1990). Applicants at most US medical schools are selected by admissions committees comprised of basic science and clinical faculty members, community physicians, and current medical students (AMA, 2003). Completed applications are typically screened and evaluated by admission office staff. Next, qualified applicants are invited to campus for interviews with designated members of the selection committee. The interviewer evaluations and applicant materials are compared with those of other applicants, and usually are presented to the admissions committee for the final admissions decisions (AMA, 2003).

The admission process is intensely competitive and serving on the admissions committee may be one of the most important responsibilities of medical school faculty members (Tutton \& Price, 2002). Selection committees are charged with evaluating each student's potential during this rigorous admission process. Information garnered from the screening of applications and interviews is used to assess cognitive and noncognitive skills in order to predict an applicant's success as a medical student (Van Susteren, Suter, Romrell, Lanier, \& Hatch, 1999). In order to develop procedures that use objective data, admissions committees rely on empirical studies that examine the relationship of applicants' past academic performance to success in medical school (Veloski, Callahan, Xu, Hojat, \& Nash, 2000). These studies support the use of academic skill indices predictors.

Many models have been developed and utilized to select applicants who are the most likely to succeed in medical school (Kulatunga-Moruzi \& Norman, 2002a). These 
models have relied heavily on traditional academic predictors such as MCAT scores, CGPA, and SGPA. A robust relationship between these academic measures and successful completion of the basic sciences in medical school is reported (Hall \& Bailey, 1992; Jones \& Thomas-Forques, 1984; Mitchell, Haynes, \& Koenig, 1994).

In order to aid in the systematic evaluation of these academic predictors, most applicants to U.S. medical schools provide transcripts, MCAT scores, and a standardized application form. The AMCAS provides a standardized application form, which can be sent to most U.S. medical schools. This form requests demographic information as well as previous academic indices (CGPA, SGPA, and MCAT scores). Most US medical school admission committees require submission of the AMCAS, MCAT scores, transcripts, letters of recommendation, an essay, confirmation of legal residency, and other college forms (AMA, 2003).

The MCAT is a standardized assessment, it is designed to assess scientific problem solving, critical thinking, and writing skills as well as knowledge of science content and concepts required for the study of medicine. These are assessed via multiple choice and writing sample components (AMA, 2003). This assessment provides admission committees with a standardized measure of these variables under equivalent conditions. The MCAT is divided into four sections: Verbal Reasoning, Physical Sciences, Biological Sciences, and Writing Sample. Scores for each section are reported, ranging from a low of 1 to a high of 15 , and as of 2003 a composite score of the first three sections is now provided. A review of data from the American Medical Data Warehouse 2001 Applicant Matriculant file suggests that no single score on an MCAT section guarantees applicants admission into medical school (AMA, 2003). These data do 
suggest, however, that applicants with scores of 10 or above in the Verbal Reasoning, Physical Science and Biological Sciences are more likely to be accepted into medical school.

Undergraduate cumulative and science grade point averages of medical school applicants are also evaluated. A review of data from the American Medical Data Warehouse 2003 Applicant Matriculant File suggests that most applicants have both cumulative and science undergraduate GPAs between 3.50-3.75. Applicants with GPAs in these ranges and above were more likely to be accepted into medical school. It is important to note, however, that a significant number of applicants with scores in these ranges were not accepted, underscoring that a variety of factors are considered in the admissions process (AMA, 2002).

Assessing personality qualities of applicants is also a critical component of the medical school admissions process (McGaghie, 1990; Johnson \& Edwards, 1991; Kulatunga-Moruzi \& Norman, 2002a). These qualities are often assessed by evaluating letters of reference and short answer essays, as well as interpersonal characteristics during the interview process (AMA, 2002). Interviews are the most widely used method of assessing personality characteristics (Kulatunga-Moruzi \& Norman, 2002b; Edwards, Johnson, \& Molidor, 1990; Van Susteren, Suter, Romrell, Lanier, \& Hatch, 1999). Mitchell (1990) suggests that $99 \%$ of US medical schools surveyed require some form of interview. In their review of the medical school admissions process, Edwards and colleagues (1990) suggest that interviews were rated as one of the most critical components of the selection process, followed by undergraduate science GPA, cumulative GPA and letters of reference, MCAT scores and undergraduate nonscience 
GPA. Interviews are a time honored method for assessing medical school applicants skills and personal qualities, yet a number of related studies in the private sector suggest that this method is often an unreliable predictor of subsequent performance (Huffcutt \& Arthur, 1994). Findings by Meit, Borges, Cubec, and Yesek, (in submission) suggest that medical students tendency to rate themselves higher on personality traits which are “socially acceptable"(friendliness, maturity, responsibility, and sensitivity), may inhibit applicants ability to accurately depict themselves during interviews. These findings underscore the difficulties associated with assessing personality qualities which are faced by interviewers.

A related issue surrounds the assessment of personal qualities during this selection process (Kulatunga-Moruzi \& Norman, 2002b). Varying opinions exist regarding which characteristics correlate with success. McGaghie (1990) suggests that integrity, leadership ability, communication skills, work ethic, and orientation to service are central to success in the field of medicine. The AMA (2003) suggests that a number of personality qualities are assessed during the application and interview process, including: psychological maturity, character and integrity, judgment, empathy, communication skills, concern for helping others, intellectual curiosity and enthusiasm, motivation, leadership skills, and experience in, and knowledge of the medicine field.

While the assessment of these noncognitive characteristics as well as others is acknowledged as valuable in the selection process of medical students, significant difficulty in reliability and validity exists. Difficulties with inter-rater reliability (Kulatunga-Moruzi \& Norman, 2002a), and interview rating bias (Edwards et al., 1990) have also been found. 


\section{Related Medical School Culture/Climate Issues}

The medical school admissions process is intensely competitive and undoubtedly characterized by stressors that are unique to this process. The process of medical education has also been described as uniquely stressful (Lee \& Graham, 2001). In fact, during the last ten years, dozens of "self help," and "medical school survival" resource guides have been published in the U.S. and abroad. Stressors typically experienced and reported by medical students include: academic, relational, and personal (Carmel \& Bernstein, 1987), and more specifically; time pressure, frequent evaluation, limited time for personal recreation and relationships, peer competitiveness, rote memorization of large amounts of material, and increasing responsibilities associated with caring for patients (Lee \& Graham, 2001). How students manage these stressors may well be a function of personality. Henning and Shaw (1998) suggest that medical students with higher levels of self and other-oriented perfectionism report higher levels of distress, suggesting more limited coping ability. Stressors and their requisite coping responses, as well as the personality traits which shape them, may very well impact both the training and retention of medical students.

Literature regarding this venerable but vulnerable population suggests they show a generally higher prevalence of depression, anxiety, and alcohol/drug abuse (Brooke, Edwards, \& Taylor, 1991; Firth-Cozens, 1997; Flaherty \& Richman, 1993; Tyysen et al., 2001). Higher rates of suicide attempts and completions in physicians have also been reported in the research (Lindeman, Laara, Hakko, \& Lonnquist, 1996; Richings, Khara, $\&$ McDowell, 1986). These mental health data are consistent with those reported for medical student populations. A recent study by Tyssen and colleagues (2001) reported 
the prevalence of mental health problems and need for treatment at $17 \%$ for fourth year medical students. This study also reported a reduction in help seeking behavior among medical student research participants reporting mental health concerns. As this mental health prevalence literature is reviewed, one notes the related issues of academic difficulties and susceptible personality traits and their relationship to resilience, vulnerability and help seeking behavior. Firth-Cozens (1997) suggests that research which provides salient information regarding the personality of physicians must more widely inform the discussion and resolution of these medical education issues. A metanalysis of related literature suggested that five of the reviewed studies reported that specific personality traits were predictive of future problems. Traits in the neurotic/self critical domains appeared to be most predictive of future mental health concerns in medical students and/or physicians (Tyssen \& Vaglum, 2002).

These higher rates of mental health concerns may be associated with a myriad of factors, including but not limited to, the demands of, and stressors posed by, the medical education process. This stressful process, and the hierarchy which organizes and drives it, has been described as similar to "a neglectful and abusive family system" (McKegney, 1989, p. 455). Given these factors it is logical to identify variables that might increase a student's chances for success in this stressful environment.

\section{Demographic Variables}

The use of demographic variables such as age, gender or race in the admission practices of medical schools is unlawful and inconsistent with ethical practices (AMA, 2003). An examination of the impact of these variables on attrition and retention 
however, may enable faculty members to more efficiently identify and provide support to students whose background may place them at risk for academic difficulty.

Demographics of medical students were among the first variables investigated as predictors of academic success in medical school. These characteristics include age, gender, ethnicity, race, socioeconomic status of parents, birth order, parental occupation (physician vs. non-physician), state/country of origin, psychosocial stressors, first generation student status, and learning styles have been investigated (Cariago-Lo et al., 1997). Studies suggest that the demographic variables typically associated with successful medical students include the following: age $>23$ (Ramsbottom-Lucier, Johnson, \& Elam, 1995; Feil, Kristian, \& Mitchell, 1998); male gender (Fitzpatrick \& Wright, 1995; Huxam, Lipton, Hamilton, \& Chant; 1989); European or Asian American ethnicity (Tekian, 1998; Cariaga et al., 1997); higher parental income (Fadem, Schuchman, \& Simring, 1995); urban origin in preclinical years (Peng, Khaw, \& Edariah, 1995); and first born status (Peng, Khaw, \& Edariah, 1995).

Although the data suggested robust correlations between many of the demographic variables listed above (i.e. age, gender, ethnicity), contrary findings by other investigators are also evident. For example, Simpson and Budd (1996) suggested that male medical students drop out at higher rates than their female counterparts and that more mature students persist and graduate at higher rates than predicted in the medical education literature. Other studies find that demographics related to undergraduate major, of science or math vs. humanities or social sciences (Smith, 1998); sex, ethnic group, and family size (Peng, Khaw, \& Edariah, 1995), and Asian ancestry (Veloski et al., 2000) were not correlated with academic performance. Instead, it has been suggested that a 
combination of variables affect academic performance (Smith, 1998; Peng, Khaw, \& Edariah, 1995). Haist, Wilson, Elam, Blue, \& Fossum, (2000) investigated this interaction by considering gender and age variables in combination as they correlate with medical school performance. They reported that females perform better on clinically based examinations; younger males were least likely to experience academic difficulty; and conversely, younger females were most likely to have difficulty. Their study found that older $(>23)$ female matriculants out performed their younger male, female, and similarly aged male counterparts.

\section{Cognitive Factors}

The academic skill indices variables typically studied by researchers include: undergraduate cumulative and science grade point average (GPA), and Medical College Achievement Test (MCAT) scores. Academic outcomes have generally been assessed by basic science GPA, National Board scores, clinical evaluations, academic ranks, and more recently, Objective Structured Clinical Exam (OSCE) scores (Cariago-Lo et al., 1997; Shen \& Comrey, 1997). Researchers have suggested that MCAT scores below an 8 and an undergraduate science GPA of less than 3.25 significantly increase attrition and graduation delays (Rosenfeld, Hojat, Veloski, Blacklow, \& Goepp, 1992). Higher cumulative undergraduate and science GPAs however, have been strongly predictive of academic success in medical school (Cariaga-Lo et al., 1997; Claap \& Reid, 1976; Green et al, 1993; Hall \& Bailey, 1992; Jones \& Adams, 1983; Leonardson, Cook, \& Charboneau, 1987; Mitchell, 1990; Sarnacki, 1982; Webb, Sedlacek, et al., 1997). Previous research also suggested that higher MCAT scores also strongly predict students' performance in medical school (Koenig, Sireci, \& Wiley, 1998; Mitchel et al., 1994; Swanson, Ripkey, \& Case, 1996; Wiley \& Koenig, 1996). Notably, MCAT score are consistently more 
valuable than undergraduate GPAs as predictors of performance on licensing exams (Veloski et al., 2000). This fact may be related to the variables that affect undergraduate GPA (selectivity and rigor of college and major, courses taken, grade inflation, etc.). The critical value of MCAT scores and GPAs are consistently reflected in admission practices across the nation. Along with personal interviews, these variables are typically weighted heavily (Hall \& Bailey, 1992; Johnson \& Edwards, 1991).

Powis (1994) confirmed this practice, suggesting that relying on cumulative undergraduate GPA is the simplest selection procedure used by medical school admissions committees to predict success in applicants. This procedure is consistent with the premise suggested much earlier by Gough (1978), that future academic success in medical school exams is best predicted by previous success on similar exams (i.e. past behavior predicts future behavior). Typically, medical school admissions committees develop stringent undergraduate cumulative and science grade point averages requirements (Powis, 1994). The literature provides little clear direction on precisely how to establish these cut-offs. Typically, medical school admission committees and administrative teams rely on careful analysis of performance data of current students and former graduates (AMA, 2002). Research does confirm this premise, that past undergraduate and MCAT performance predicts future performance in medical school, and therefore supports this admissions practice (Chan-Ob \& Boonyanaruthee, 1999; Cariaga-Lo et al., 1996; Greene et al., 1993; Hall \& Bailey, 1992; Kulatunga-Moruzi \& Norman, 2002b; Leonardson et al., 1987; Mitchell, 1990; Montague \& Odds, 1990; Scott, Greig, Brock, Hunt, Shead, \& Carline, 1988; Weiss, Lotan, Kedar, \& Ben-Shakhar, 1988). These studies suggested that high undergraduate GPA and/or MCAT scores are 
robust predictors of academic success in medical school. Cariaga-Lo and colleagues (1997) further suggested that as undergraduate science GPA increases, the risk of failure or attrition decreases (risk ratio of .58). Similar results were also evident for cumulative undergraduate GPA (risk ratio of .6) and MCAT scores (risk ratio of .91). In other words, the higher the score on these critical academic indices, the more likely a student would ultimately graduate.

These findings are evident in research by Hodgeson and Silver (1997) who evaluated GPAs and MCAT scores as predictors of National Board of Medical Education Exams I (NBME) and clerkship performances. This study assessed relationships between undergraduate student characteristics, standardized indicators of academic performance, and clinical performances. The author confirmed that MCAT scores and cumulative undergraduate GPA were significantly related to performance on the NBME I (as were gender and country of origin). Hodgeson and Silver (1997) suggests however, that although cumulative undergraduate GPA and MCAT scores are strong predictors of NBME I performance, they are not reliable predictors of clinical performance. This conclusion suggests that the skills required in years 3 and 4 of medical school may in fact be different from those skills predicted by high GPA and MCAT scores.

A comprehensive study by Tekian (1998) cautioned against using academic indices predictor variables and analyzed a number of variables as predictors of success in medical school including: students, current status, average MCAT score, undergraduate GPA (cumulative and nonscience), a cognitive index assigned by the admission committee that accounted for a student's MCAT score, GPA (weighted by the competitiveness of the undergraduate institution), number of attempts to pass the United 
States Medical Licensing Exam (USML) steps 1 and 2, and number of attempts to pass core clerkships for 350 students who matriculated at the University of Illinois College of Medicine. Notably, higher undergraduate GPAs and MCAT scores for members of both minority and nonminority groups were modestly correlated with increased chances for success in medical school (i.e. graduation). The author suggested that minority and nonminority students who delayed graduation appeared to have much higher cognitive indices than anticipated, and reported experiencing significant negative life events at much higher rates during this time period. This must be considered a confounding variable. Tekian (1998) cautiously suggested that the cognitive indices utilized have some merit as predictors but are not sufficiently sensitive to differentiate between at risk students who will withdraw, delay graduation, or graduate. This conclusion is particularly salient for medical students who are of minority status.

Modest predictor relationships between high undergraduate GPA and academic success in medical school are also suggested by other studies (Hall \& Bailey, 1992; Shelldrake, 1975). These studies suggested that other variables exist which must be considered and that the correlation between high undergraduate GPA and success in medical school becomes less salient as students enter the last two years of their medical education (as suggested later by Hodgeson \& Silver, 1997). This observation is consistent with the shift from basic sciences to clinical training during the last two years of medical education, and is amplified in a related study that attempted to identify admission criteria that predict performance in the first postgraduate year (internship).

Related research also found that undergraduate GPA, (along with a range of other variables including age, gender, undergraduate science major, and admission interview 
results were not predictive of intern performance rating (Rolfe, Pearson, Powis, \& Smith, 1995). In other words, undergraduate GPA may predict academic success in the basic sciences but may be less predictive of success in clinical training. Similarly, other studies suggested that academic achievement (especially as a sole predictor criterion) is a poor predictor of effectiveness as a physician (Gunzberger et al., 1987 in Powis, 1994; Sade, Stroud, Levine, \& Fleming, 1985).

Although this predictor research typically finds positive relationships between MCAT scores, prior GPA and performance in medical school, these findings were not supported in studies by Shen and Comrey (1997) and Green and colleagues (1991). Shen and Comrey suggested that due to the very limited variability of the undergraduate grade point averages they used as predictors, their predictive values were lost. They further suggested that when used together, students' personality characteristics and MCAT scores can more effectively predict medical school performance. When using both personality characteristics and MCAT scores, predictability of medical school performance increased from $20 \%$ to $50 \%$.

\section{Personality Characteristics Variables}

Sade and colleagues (1985) argued that although a number of these studies have suggested that many of these academic indices predict academic success in medical school, the more salient issue is: Do these academic variables predict which applicants will become good physicians? This question is a more difficult one to answer. Studies that assess personality traits of medical students may, however, shed light on these very issues and those regarding attrition and retention. Studies that investigate relationships between these personality, demographic, and cognitive indices variables and academic 
success (i.e. matriculation, course grades, NBME subtest scores) are reported less frequently in the literature.

Despite the typically held belief that competence of physicians is derived from both cognitive abilities (as reflected by their academic performance) and personal qualities, much less research has been completed on the latter. Debates regarding which specific personality characteristics correlate with medical student performance in the preclinical years (Hojat et al., 1993; Lievens et al., 2002; Powis, 1994; Shen \& Comrey, 1997) and clinical years are evident in the literature. This debate continues largely because of the difficulty in drawing conclusions across studies, which have used a number of different personality assessments (Lievens et al.).

Although American medical education has undergone a number of transformative changes in the last century, biomedical constructs continue to be heavily emphasized in the curriculum (McGaghie, 1990) Recently, however, the need for increasing numbers of primary care physicians and sweeping changes in the health care delivery system, have challenged this emphasis on biomedical content. Medical school faculty are suggesting that curricula be modified to emphasize more heavily the interpersonal skills required to be a successful physician (Elam, 2004, Inui, Williams, \& Goode, 1998; Spooner 1990). These skills commonly referred to in the popular media and by social psychologists as "emotional intelligence" include such qualities as empathy, compassion, and maturity. This construct is conceptualized as a specific type of social intelligence involving the ability to observe and analyze one's own and others' emotions, to differentiate among them, and finally, to utilize this information to inform and guide cognitions and behavior: i.e. perceiving, understanding, and regulating emotions (Selovey \& Mayer, 1990). In his 
book, Emotional Intelligence, Coleman (1995) expands earlier definitions, reviewing five principles of emotional intelligence: (a) knowledge of one's own emotions; (b) the ability to manage one's emotions in difficult situations; (c) motivating oneself; (d) the ability to recognize emotions in others; and (e) interpersonal skills. The relationship between these skills and success in medical student or in the practice of medicine has received little attention in the literature (Elam, 2004). Elam however, suggests that as medical school admission officers seek ways to enhance their selection processes they should consider the assessment of emotional intelligence. He suggests that these domains may both inform the admissions process as well as, shape the curriculum. Although the relationship between emotional IQ and success in medical school is unclear, a recent study Lam and Kirby, (2002) with undergraduate subjects suggests a positive relationship with higher levels of emotional success and cognitive performance. These findings may well have utility with medical school students.

A number of these personality assessment instruments have also been utilized to attempt to define "a medical personality" to predict residency choices, and to more fully understand predictors of retention and attrition for medical students. The Myers-Briggs Type Indicator (Friedman \& Slatt, 1988); California Personality Inventory (Gough, 1971; Hobfell, Anson, \& Anonvsky 1982; Tutton, 1996); Minnesota Multiphasic Personality Inventory (Dorr, 1981; Schofield, 1953), Sixteen Factor Personality Questionnaire (Borges \& Osman, 2001; Green et al., 1993; Lipton et al., 1984; Meit, Meit, \& Yaseck, 1999; Peng et al., 1995); and Comrey Personality Scales (Shen \& Comrey, 1997) have been used to identify personality traits of medical students. These assessments attempted 
to measure a very divergent set of personality traits, thus rendering the process of drawing conclusions from and across these data difficult.

Despite these difficulties, a number of studies have been conducted in the last two decades that attempted to identify a personality type or constellation/pattern of traits that could be used to predict academic success in various populations. The personality traits in the literature typically associated with academic success in medical school include: honesty, confidentiality, mental toughness, warm heartedness, respect for others and the law, empathy, perseverance, tolerance for ambiguity, compulsiveness, extraversion, agreeableness, perseverance, aggressiveness and encouraging behavior (Nath, 1987; Robbins et al., 1983; Shen \& Comrey, 1997). Conversely, medical school dropouts have been found to have higher levels of gregariousness and excitement seeking, along with lower self-achievement and self-discipline levels (Lievens at al., 2002). Lievens and colleagues hypothesized that this latter combination of personality traits represented a potentially acute risk of attrition.

Debate persists, however, regarding which personality traits correlate with academic success in medical school (Hojat et al., 1993; Shen \& Comrey, 1997). Green and colleagues' (1993) research found that academic progress during the preclinical years was not significantly related to Global or Primary personality factors as measured by the 16PF Questionnaire (5th ed.). They failed to find that higher, or conversely, lower levels of the personality traits measured predicted academic success.

In a study similar to this proposal, Shen and Comrey (1997) investigated the relationships between personality traits (using the Comrey Personality Scale), cognitive abilities, and success in medical school. Study results confirmed that MCAT scores were 
a strong predictor of academic success in medical school, and that specific personality traits (mental toughness and emotional stability) were more highly associated with both cognitive ability and academic success. The authors suggested that different personality characteristics are incorporated into dissimilar types of medical achievement, and thus, it requires using more than one or two personality characteristics to predict success in medical school.

Cariaga-Lo and colleagues (1997) conducted a similar study also using the Comrey Personality Scale (CPS). Using a survival analysis methodological approach, this study examined cognitive and noncognitive predictors of attrition and academic problems. These results notably suggested that students who tended to be norm favoring had $123 \%$ the risk of failure in medical school. The authors also reported that students with higher self realization norms had only $72 \%$ the risk of failure, and those whose CPI scores suggested they were more likely to achieve through independent means had only $68 \%$ the risk of failure than their counterparts.

Peng, Khaw, and Edariah (1995) utilized the 16 Personality Factors Questionnaire, $5^{\text {th }}$ edition to assess personality of medical students in a similar study. The authors focused on preclinical performance $\left(1^{\text {st }}\right.$ and $2^{\text {nd }}$ years $)$ with medical students at the University of Kebangsaan in Malaysia. The results of this study suggested that the 16PF Questionnaire, $5^{\text {th }}$ edition, can be effectively used for identifying personality trait patterns in students who are likely to experience academic difficulty in the preclinical phase of their medical education. Results indicated that students who perceive themselves as being enthusiastic, venturesome, self-opinionated, imaginative, experimenting, resourceful, and driven are correlated positively with successful performance. 
Conversely, students who perceived themselves as self-assured, more reserved, emotionally less stable, and more apprehensive, tended to have less success in their preclinical courses. Nath (1987) conducted a study in Calcutta and reported similar results. His results suggested that students who were more warmhearted, attentive towards others, sociable, sympathetic (factor A); conscientious, persevering, rule bound and honest (factor G); adaptable and cheerful (Factor L); self confident (Factor O); and reported strong control over his/her emotions and general behavior (Factor C) were more apt to be successful in medical school. Given the homogeneous populations sampled in both of these studies however, the results must be applied cautiously to those born and educated in the United States.

The most recent studies reviewed regarding medical students' personality characteristics and academic performance were conducted in Europe (Lievens et al., 2002; Ferguson, James, O’Hehir, \& Sanders, 2003). Using the NEO-PI-R to assess personality traits, Lievens et al. found that openness significantly predicted academic success in year three (a clinical year). Conversely, extraversion was correlated with lower rates of academic success. The results of this study are noteworthy, suggesting that students who are less successful academically perceive themselves as more gregarious and excitement seeking, and have lower conscientiousness scores, especially for achievement striving and self-discipline factors. Ferguson and colleagues (2000) reported similar findings regarding conscientiousness. Goldberg's bipolar adjectives were used in this study to assess personality traits and researchers found that higher levels of conscientiousness were significantly correlated with higher scores on preclinical exams, and ironically, to lower scores on clinical assessments. The authors hypothesized that 
behaviors related to this domain (organization, methodicalness) may be more relevant to the factual and objective nature of preclinical learning, which ultimately translates into better clinical performance. These findings are significant and confirm previous findings, which suggest that conscientiousness is correlated with academic achievement, and conversely, gregariousness predicts lower levels of academic performance.

\section{Summary}

A review of the literature suggests that there are a variety of academic indices, demographic variables, and personality traits that may predict success in medical school. Cumulative and science undergraduate GPAs and MCAT scores appear to be robust predictors of success in precinical courses as well as graduation from medical school (Cariaga-Lo et al., 1997; Hojat, et al., 1993; Kulatunga-Moruzi \& Norman, 2002b; Rosenfeld, et al., 1992; Tekian, et al., 1996). Notably, these factors are less salient predictors of success in clinical courses (Hodgeson, 1997). Demographic factors that appear to be related to academic success in medical school include: nontraditional student age, male gender, European or Asian American ethnicity, higher parental income, urban origin in preclinical years, and first-born status (Cariaga-Lo et al.; Fadem, Schuchman, \& Simring, 1995; Fitzpatrick \& Wright, 1995; Kristian \& Mitchell, 1998; Peng, Khaw, \& Edariah, 1995; Tekian, 1998).

Several personality traits (honesty, confidentiality, mental toughness, warm heartedness, respect for others and the law, empathy, perseverance, tolerance for ambiguity, compulsiveness, perseverance, aggressiveness and encouraging behavior) also appear to be correlated with academic success in medical school (Ferguson et al., 2003; Lievens et al., 2002; Nath, 1987; Robbins et al., 1983; Shen \& Comrey, 1997). These 
findings, however, tend to be less consistent than the findings in the literature regarding other predictors of success in medical school.

In reviewing these findings and in considering the rising costs and inherent difficulties associated with medical school admissions processes, two areas of need arise. The first relates to identifying strategies based on factors that correlate to student success. The second is identifying students who, although potentially successful, exhibit characteristics that place them at risk for attrition. When these students who exhibit at risk characteristics are identified early, personal and academic support can be provided before significant difficulties are encountered. Timely, well-planned interventions may assist these students in meeting and mastering the rigors of medical school. Issues related to retention, attrition, and more specifically, identifying salient personality and cognitive predictors, have in fact, been identified as a priority by the AMA (AMA, 2003).

This review suggests that the medical education environment is stressful and competitive. The relationship of personality traits to the successful navigation of this stressful environment is not clear. Certain personality traits and specific cognitive abilities as measured by undergraduate GPA (both cumulative and science) and MCAT scores may play salient roles in predicting academic success in medical school. Their precise predictive role, and specifically, which personality characteristics are predictive and correlated with success in medical school, and their relationship to one another merit further investigation

\section{Present Study}

The primary purpose of this study is to determine if specific personality trait and/or trait patterns as measured by the 16 Personality Factors Questionnaire, $5^{\text {th }}$ edition, 
undergraduate GPA (cumulative and science), and MCAT scores are correlated with success (or lack thereof) in medical school. Secondary to this effort will be a review of any correlations between cognitive factors (MCAT, cumulative undergraduate and science GPA), medical student demographics (gender, age, race) and academic success in medical school. The results of this study will be primarily descriptive and correlational. 


\section{CHAPTER 2}

\section{METHOD}

This section provides a summary of the procedures and the methodology used in this study. First, the participants are described and the details regarding the instrumentation and data collection methods are provided. Next, a description of the procedures and finally a review of the proposed data analysis methods are given Participant and Population Parameters

Data for this study were drawn from an existing database of information gathered from medical students at West Virginia University, a Mid Atlantic college. Data from three medical school classes were used and included graduates and dropouts from 2001, 2002, and 2003 for a total of 250 participants.

\section{Procedures}

This study was part of larger longitudinal project undertaken by Dr. Scott Meit, PsyD., ABPP, Director of Behavioral Science Education at West Virginia University. Dr. Meit has conducted and published the results of studies using the 16PF Questionnaire (5th ed.). As a part of the original study, each participant completed an informed consent sheet prior to the administration of the 16PF Questionnaire (5th ed.). The assessment was scheduled as a component of new student orientation. A standardized statement was read which explained the purpose of the study; assessment of personality traits, and their correlation with residency selection as well as other factors related to medical education. The completed 16PF Questionnaires (5th ed.) were coded to preserve anonymity. The responses to the 16PF Questionnaire (5th ed.) were scored according to the practices and procedures provided in the administrator's manual. 
Demographic data for the participants were provided in a database format by the Office of Student Affairs in the WVU School of Medicine. These data were collected as part of broader administrative retention efforts and are derived from AMCAS applications to the WVU school of Medicine.

\section{Instruments}

The 16PF Questionnaire ( $5^{\text {th }}$ ed.) was used to assess personality traits of the study participants. Translated into over forty languages, it has been used in a variety of industrial, organizational and educational environments (Conn \& Rieke, 1994). It assesses primary personality traits, which are constructed into essentially normal “factors” or clusters (Conn, \& Reike; Karson, Karson, \& O’Dell, 1997). The 16PF was developed by Cattell, forty-seven years ago to measure the primary components of personality (Cattell \& Cattell,1995). Notably, it was the first test derived from systematic scientific research which examined personality traits. Cattell suggested that the assessment of personality traits and patterns would provide a more clear understanding of the person, enabling predictions to be made regarding future behavior (Engler, 1979). Engler suggested that Cattell differentiated between two types of traits: surface and source. Surface traits were identified as observable behaviors, which tend to be linked together. Conversely, source traits are environmentally or dispositionally determined and refer to the variables, which establish surface manifestation (Halls \& Lindsey, 1978 as cited in Borges, 1998). The 16 PF Questionnaire $\left(5^{\text {th }}\right)$ identifies 5 broad personality categories referred to as Global Factors and 16 personality categories called Primary Personality Factors (Cattell, Cattell, \& Cattell, 1993). Since the first publication, the 16 PF has undergone four revisions $\left(1956,1962,1967,1969\right.$, and 1993). The $5^{\text {th }}$ edition of 
the $16 \mathrm{PF}$ included the Global Factors and various other criterion related scales (Russell \& Carol, 1994).

The 16PF Questionnaire $\left(5^{\text {th }}\right)$ is a self administered questionnaire written at a fifth grade reading level, which is intended for individuals over the age of 16 (Russell \& Carol, 1994). Female, male and combined sex norms are available. Administered individually or in group settings, completion time is approximately 35 to 50 minutes manually, or 25-35 minutes electronically. The instrument is comprised of 185 items, which assess five Global Factors: Extraversion, Anxiety, Tough Mindedness, Independence, and Self Control and 16 Primary Factors. They are Warmth, Reasoning, Emotional Stability, Dominance, Liveliness, Rule Conscious, Social Boldness, Sensitivity, Vigilance Abstractness, Privateness, Apprehension, Openness to Change, Self Reliance, Perfectionism, and Tension.

The scales that measure each factor contain approximately 10-15 items. All 16PF questionnaire items, except for 15 items from Factor B (which assesses abstract reasoning ability), provide three response options, with the middle choice being a question mark representing a "middle" option, enabling respondents to indicate their uncertainty regarding an item. Items from Factor B are separated from the other items because reasoning items have correct responses, while personality items do not.

Three additional validity scales are provided: Impression Management Scale (IM), Acquiescence Scale (ACQ), and the Infrequency Scale (INF). The IM scale assesses social desirability. The ACQ scale assesses the respondent's need for approval, measuring their need to respond affirmatively (content not withstanding). The INF scale can suggest random, atypical response patterns. 
Raw scores are converted to scores on a standard continuum ranging from 1 to 10 , known as a "sten." A sten of 10 represents the highest perception of the assessed personality factor; conversely, a score of 1 represents the smallest perception of the assessed personality factor. The mean sten score for each assessed personality trait is 5.5 with a standard deviation of 2.0 (Russell \& Carol, 1994). The 16PF Questionnaire (5th ed.) was normed on a sample of 2,500 persons (1,255 females and 1,245 males), ranging from 15 to 92 years of age, with a mean age of 33.3 years and mean education level of 13.6 years (Conn \& Rieke, 1994). In obtaining the normative sample, efforts were made to stratify the selection by gender, race, age, and education to obtain demographic variable percentages which were comparable to the 1990 census (Conn \& Rieke). Normative groups were updated in 2000 .

The technical manual of the 16PF Questionnaire $\left(5^{\text {th }}\right.$ ed.) also provides critical validity and reliability information. Reliability is reviewed in the following paragraphs for (a) Test Retest Reliability (stability) and (b) Internal Consistency Reliability. Validity is reviewed for (a) Construct Validity and (b) Criterion Validity.

Test Retest Reliability coefficients for the 16PF questionnaire $\left(5^{\text {th }}\right.$ ed.) for the 16 primary factors over a two week interval were reported as ranging from .69 (Reasoning) to .86 (Self Reliance) (Conn \& Rieke, 1994). Global Factor Retest coefficients were somewhat higher, ranging from .84 to .91 with a reported mean of .87 . Notably, six of the primary scales and four of the secondary scales exhibited significant stability over a six year time period (Bolton, 1979). 
Internal scale consistency of the 16PF was assessed with Cronbach's alpha coefficient. Values ranged from .64 (Openness to Change) to .85 (Social Boldness), with a reported mean of .74 .

Construct validity of the 16PF Questionnaire (5th ed.) was assessed using the Myers-Briggs Type Indicator (MBTI), NEO PI-R and California Psychological Inventory (CPI) and $\backslash$ was demonstrated using factor analysis procedures (Conn \& Rieke, 1994). Correlational, regression and factor analyses provide considerable support evidence for the global factor scales. The primary scale demonstrating the most change was Abstractness (Conn \& Rieke). In earlier versions of the 16PF, Abstractness was demonstrated to pertain only to abstract thought. In the most recent version $\left(5^{\text {th }}\right.$ edition $)$, this scale was shown to be related also to self-control characteristics (Conn \& Rieke). The meaning of Privateness and Openness to Change scales were also altered in the $5^{\text {th }}$ edition. Factor analysis of the Privateness category suggests that this scale presently shares aspects of the Surgency scale. Analysis of the Openness to Change scale in the 16 PF Questionnaire (5th ed.) may in addition to measuring preference for change, assess how an individual copes with this change.

Comparison of the second order factors in the $4^{\text {th }}$ and the Global factors in the $5^{\text {th }}$ editions of the $16 \mathrm{PF}$ demonstrates a high degree of congruence with correlations ranging from.65-.81 for four of the five scales. The lowest correlation was demonstrated between the $5^{\text {th }}$ edition, Toughmindness and $4^{\text {th }}$ edition, Tough Poise $(r=.38)$ (Conn \& Rieke, 1994). This finding reflects omission of items regarding dominance and aggression in females in the $5^{\text {th }}$ edition (Conn \& Rieke). A more detailed summary of both construct and criterion validity can be found in the 16PF Questionnaire (5th ed.) Technical Manual. 


\section{Research Questions}

Research questions and hypotheses address relationships between (a) demographic data, (b) academic predictors, and (c) personality traits and academic success in medical school.

Research Question 1: Are selected demographic characteristics related to graduation rates and academic performance quartile rankings? This research question is derived from a review of related studies by the following investigators: Cariaga-Lo et al. (1996); Fitzpatrick and Wright (1995); Ramsbottom-Lucier, Johnson, and Elam (1995); and Tekian (1998).

Research Hypothesis 1.1: Male students participating in medical school programs will graduate from medical school at higher rates than female students and will achieve higher academic performance quartile rankings. This hypothesis is derived from a review of related findings by Fitzpatrick and Wright (1995) and Huxam, Lipton, Hamilton, and Chant (1989).

Research Hypothesis 1.2: Nonminority students will graduate from medical school at higher rates and will achieve higher academic performance quartile rankings than their minority counterparts. This hypothesis is derived from a review of related findings by Cariaga-Lo and colleagues (1997) and Tekian (1998).

Research Hypothesis 1.3: Traditionally aged $(<23)$ medical students at the time of entry will graduate from medical school at higher rates and will achieve higher 
academic performance quartile rankings than their older peers age 23 and above. This hypothesis is derived from a review of related findings by Feil, Kristian, and Mitchell (1998), and Ramsbottom-Lucier, Johnson, and Elam (1995)

Research Question 2: Are undergraduate GPAs and MCAT scores earned prior to acceptance to medical school related to graduation rates and academic performance quartile rankings in medical school? This research question is based on review of the research findings of the following investigators: Cariaga-Lo et al. (1997); Claap and Reid (1976); Green et al. (1993); Hall and Bailey (1992); Koenig et al. (1998); Sarnacki (1982); Swanson et al. (1996); Webb et al. (1997); Wiley \& Koenig (1996).

Research Hypothesis 2.1: Students with higher cumulative undergraduate GPAs will graduate from medical school at higher rates and will achieve higher academic performance quartile rankings than their peers with lower cumulative undergraduate GPAs. This Research Hypothesis is based on a review of related research findings of the following investigators: Cariaga-Lo et al. (1997); Claap and Reid (1976); Green et al. (1993); and Hall and Bailey (1992).

Research Hypothesis 2.2: Students with higher science undergraduate GPAs will graduate from medical school at higher rates and will achieve higher academic performance quartile rankings than their peers with lower science undergraduate GPAs This research hypothesis is based on a review of related research of ChanOb and Boonyanaruthee (1999). 
Research Hypothesis 2.3: Students with higher MCAT scores will graduate from medical school at higher rates and will achieve higher academic performance quartile rankings than their peers with lower MCAT scores. This research hypothesis is based on a review of related research findings of the following investigators: Koenig et al. (1998); Kutalunga-Moruzi, and Norman (2002a, 2002b); Mitchell et al. (1994); Swanson et al. (1996); Shen and Comrey (1997); Tekian (1998); Wiley and Koenig (1996).

Research Question 3: Are the personality traits as measured by the 16PF Questionnaire (5th ed.) related to graduation rates and academic performance quartile rankings? This Research Question is based on a review of the research findings of the following investigators: Clap and Reid (1976); Cariaga-Lo et al. (1997); Ferguson et al. (2003); Green et al. (1991); Lievens et al. (2002); Hall and Bailey (1992); Webb et al. (1997). Research Hypothesis 3.1: Lower levels of assessed Extraversion are related to higher graduation rates and academic performance quartile rankings in medical school. This research hypothesis is based on findings by Lievens et al. (2002).

Research Hypothesis 3.2: Lower levels of assessed Anxiety are related to higher graduation rates and academic performance quartile rankings in medical school This research hypothesis is based on a review of related research findings of Lievens et al. (2002). 
Research Hypothesis 3.3: Higher levels of assessed Tough Mindedness are related to higher graduation rates and academic performance quartile rankings in medical school. This research hypothesis is based on a review of related research findings of Shen and Comrey (1997).

Research Hypothesis 3.4: Higher levels of assessed Independence are related to higher graduation rates and academic performance quartile rankings in medical school. This research hypothesis is based on a review of related research findings of the following investigators Shen and Comrey (1997).

Research Hypothesis 3.5: Higher levels of assessed Self Control are related to higher graduation rates and academic performance quartile rankings in medical school. This research hypothesis is based on a review of related research findings of Nath (1987).

Research Hypothesis 3.6 Some of the 16 PF Primary Factors are related to higher graduation rates. This Research Hypothesis is based on a review of related research findings by Peng et al. (1995).

\section{Design and Analysis}

The dependent variable for this study is Graduate Status Ranking Group (first, $25 \%$, second $25 \%$, third, $25 \%$, fourth, and $25 \%$ percentiles) the independent variables are:

1) Demographic characteristics (age, gender, race). 
2) The cognitive indices variables (MCAT, CGPA and SGPA).

3) The 16PF Questionnaire (5th ed.) with 5 Global Factors and 16 Primary Personality Factors.

Power Analysis. This study used a .05\% alpha level. Beta was calculated at .20 (or 4 times alpha), which enabled the researcher to establish a desired level by setting the Type II error at four times the rate of making a type I error (Rosenthal, 2001). A power estimate for this study was derived by subtracting Beta from 1.00, providing an estimated power level of .80 . Next, a desired sample size was calculated to achieve this .80 power level. To obtain an expected effect size of medium in a four-group study, 44 participants per group were required. A medium effect size was chosen to decrease the probability of type I errors. Effect size was calculated to quantify the size of the difference between groups (i.e. to indicate the strength of these relationships). Effect size was also calculate in an attempt to standardize the difference between groups.

Data Analysis. Preliminary analysis of the data included descriptive statistics for the dependent variables (graduation status and academic performance quartile ranking) and independent variables (gender, minority status, age at entry, MCAT composite score, CGPA, and SGPA and the 16PF Global and Primary Factors). The collected data was analyzed using SPSS.

The research questions were analyzed using Chi-Square and One-way Analyses of Variance (ANOVA). Chi square is a non-parametric test of statistical significance. It enabled the researcher to know the degree of confidence experienced in rejecting or accepting the hypotheses. Using ANOVAs enabled the researcher to evaluate how much the mean values of a numerical variable differed among the categorical variable 
categories. Tukey Post Hoc Tests were conducted when the ANOVAs yielded significant results. Tukey Post Hoc Tests enabled the researcher to determine which group means differed from one another. To more fully control for error in hypothesis 3.6 , the significance level was adjusted to 025 .

Separate Chi Square and ANOVA's were generated as follows:

Research Question 1: Are selected demographic characteristics related to graduation rates and academic performance quartile rankings? Six Chi Square analyses were conducted to test the relationship between demographic characteristics and graduation rated and academic performance quartile rankings. The independent variables for this hypothesis were categorized and coded as follows:

- Sex: Male (1) and Female (2)

- Race: White(2) and all other minority groups (1)

- Age: Less than 23 years (1) and 23 years or higher (2)

The dependent variables for this hypothesis were categorized and coded as follows:

- Graduation Status: Graduated (1) and Not graduated (2)

- Quartile Ranking: 76-100 (1), 51-75 (2), 50-26 (3) and 1-25 (4).

Research Question 2: Are undergraduate GPAs and MCAT scores earned prior to acceptance to medical school related to graduation rates and academic performance quartile rankings in medical school? Six ANOVA's and Tukey Post Hoc Tests as indicated were conducted to test the relationship between undergraduate GPAs and MCAT and graduation rated and academic performance quartile rankings. The independent variables for this hypothesis were categorized and coded as follows: 
- Cumulative GPA (continuous variable)

- Science GPA (continuous variable)

- MCAT score (continuous variable)

The dependent variables for this hypothesis were categorized and coded as follows:

- Graduation Status: Graduated (1) and Not graduated (2).

- Quartile Ranking: 76-100 (1), 51-75 (2), 50-26 (3) and 1-25 (4).

Research Question 3. Are the personality traits as measured by the 16PF Questionnaire (5th ed.) related to graduation rates and academic performance quartile rankings? 20 ANOVA"s and Tukey Post Hoc Tests as indicated as indicated were conducted to test the relationship between personality traits and graduation rated and academic performance quartile rankings. The independent variables for this hypothesis were categorized and coded as follows:

- Global Factors (Extraversion, Anxiety, Tough Mindedness, Independence, and Self Control).

- Primary Factors: (Warmth, Reasoning, Emotional Stability, Dominance, Liveliness, Rule Consciousness, Social Boldness, Sensitivity, Vigilance, Abstractness, Privateness, Apprehension, Openness to Change, Self Reliance, Perfectionism, and Tension).

The dependent variables for this hypothesis were categorized and coded as follows:

- Graduation Status: Graduated (1) and Not graduated (2).

- Quartile Ranking: 76-100 (1), 51-75 (2), 50-26 (3) and 1-25 (4).

Validity of the 16PF Questionnaire (5th ed.) will be established for each subject using the Impression Management (IM), Acquiescence (ACQ), and the Infrequency (INF) scales. The 16PF Questionnaires (5th ed.) manual provides recommended cut off scores 
for these three scales (Conn \& Rieke, 1994). Accordingly, surveys with validity scale scores above the 95 th percentile or below the $5^{\text {th }}$ percentile will be excluded from the data set.

Updated 16PF Questionnaire norms exist based on the 2000 census. Given the longitudinal nature of the original investigation from which the data set used in this study was derived, a decision was made by the primary investigator, Scott Meit, PsyD of the original study to continue using the 1993 norms in scoring the 16PF Questionnaires (5th ed.). This decision was made in consultation with the publishers of the $16 \mathrm{PF}$ Questionnaires (5th ed.), International Institute for Personality and Ability Testing (personal communication, Scott Meit, 2004). The data used in this study was collected prior to the change in norm group. 
Table 1

Independent and Dependent Variables, Design of the Research Dependent Variables Codes

1. Graduation Status:

2. Quartile Ranking

Codes

1: Did Graduate

Top $25 \%$ (76 to $100 \%) \quad 1$

2: Did Not Graduate

Next $25 \%(51$ to $75 \%) \quad 2$

Next $25 \%(26$ to $50 \%) \quad 3$

Bottom $25 \%$ (1 to $25 \%) \quad 4$

Independent (Predictor) Variable Codes for Research Questions 1

$\underline{\text { Variable }}$

Hypothesis 1: Sex Hypothesis

Hypothesis 2: Age Category

Hypothesis 3: Race

\section{$\underline{\text { Codes }}$}

1 is male, 2 is female

1 is less than 23,2 is 23 yrs and (+)

White: 2

Minority: 1

Independent (Predictor) Variables for Research Question 2

$\underline{\text { Variable }}$

Hypothesis 1: Cumulative GPA

Hypothesis 2: Science GPA

Hypothesis3: MCAT $\underline{\text { Range }}$

0.0 to 4.0

0.0 to 4.0

0.0 to 60 
Independent (Predictor) Variables for Research Question 3

16PF Five Global Factors

Hypothesis 1: Extraversion

Hypothesis 2: Anxiety

Hypothesis 3: Tough-Mindedness

Hypothesis 4: Independence

Hypothesis 5: Self-Control
\# of Items

51

40

47

44

42
Sten Range

$1-10$

$1-10$

$1-10$

$1-10$

$1-10$

$1-10$

Hypothesis 3.6: Warmth

Emotional Stability

1-10

Dominance

10

1-10

Liveliness

10

1-10

Rule Consciousness

10

1-10

Social Boldness

11

1-10

Sensitivity

10

$1-10$

Vigilance

11

1-10

Abstractness

10

$1-10$

Privateness

11

1-10

Apprehension

10

$1-10$

Openness to Change

10

1-10

Self-Reliance

14

1-10

Perfectionism

10

$1-10$

Tension

10

1-10 


\section{CHAPTER 3}

\section{RESULTS}

The analysis cohort for this study consisted of 250 medical students from West Virginia University. The demographics for this sample are available in Table 2. The participants were from three medical school cohorts (graduation dates: 2001, 2002, and 2003). One hundred and fifty five (62\%) were male and 95 (38\%) female. Ethnic/racial demographics of the sample $(\mathrm{n}=198,79.2 \%)$ were Caucasian American, followed by Asian American $(n=46,18.4 \%)$, Hispanic Americans $(n=3,1.2 \%)$ African Americans, $(\mathrm{n}=2, .8 \%)$ and Native American $(\mathrm{n}=1, .4 \%)$. The majority of participants were less than 23 years of age $(n=212,85.1 \%)$, and $37(14.9 \%)$ were 23 years of age or older. The majority graduated from medical school $(\mathrm{n}=221,84 \%)$. Twenty nine participants (11\%) did not graduate. Academic quartile ranking data were available for 169 of these participants and are broken down as follows: quartile ranking one, $n=43$, 25.4\%; quartile ranking $2, \mathrm{n}=43,25.4 \%$; quartile ranking $3, \mathrm{n}=42,24.9 \%$; and quartile ranking $4, \mathrm{n}=41,24.3 \%$.

\section{Research Question One}

Research Hypothesis 1.1 proposed that male sex would be related to higher medical school graduation rates and higher academic performance quartile rankings. To test this hypothesis, a Chi-Square analysis was conducted to determine the relationship between sex and graduation status. $(1=$ graduated, $2=$ not graduated by $1=$ male, $2=$ female). Sex constituted a discrete variable which was nominal in nature. Results of this Chi-Square analysis are reported in Table 3. The Chi-Square analysis did not yield a 
statistically significant finding between sex and graduation statuses, Chi-Square $(1)=0.0$, $p=.99$

A second Chi-Square was calculated to examine sex ( $1=$ male, $2=$ female $)$ compared to quartile ranking, $\left(1=1^{\text {st }}\right.$ quartile, $2=2^{\text {nd }}$ quartile, $3=3^{\text {rd }}$ quartile, and $4=4^{\text {th }}$ quartile) and constituted an ordinal group variable. Results of this analysis are reported in Table 3. This analysis did not yield a statistically significant relationship among the four quartile ranks and sex, Chi-Square $(3)=2.88, p=.41$.

Research Hypothesis 1.2 proposed that nonminority student status would be related to higher medical school graduation rates and higher academic performance quartile ranking. A Chi-Square analysis was conducted to determine the relationship between nonminority status and graduation status. Minority status constituted a discrete variable which was nominal in nature. The homogeneity of the sample limits the results of the analysis. The following categories were created to investigate this hypothesis: $1=$ White; $2=$ Native American, African American, Asian, and Hispanic; by $1=$ graduate, 2 $=$ not graduated. Results of this analysis are reported in Table 4. This analysis yielded a significant finding between these prescribed minority categories and the two graduate statuses, Chi-Square 1) $=.81, p=.01$. Although this analysis was completed in order to address the research hypothesis, it will not be reported in the literature as a significant finding because of the small $\mathrm{N}$ (i.e. one student in the minority/did not graduate cell). .

The relationship between academic performance quartile ranking and minority status was investigated using Chi-Square analysis procedures. The following categories were created to investigate this hypothesis: $1=$ White and $2=$ All other minority groups (Native American, African American, Asian, and Hispanic) by $1=1^{\text {st }}$ quartile, $2=2^{\text {nd }}$ 
quartile, $3=3^{\text {rd }}$ quartile, and $4=4^{\text {th }}$ quartile. The independent variables were compared to quartile ranking and constituted an ordinal group variable. Results of this analysis are reported in Table 4. This analysis did not yield a statistically significant finding between these prescribed minority categories and quartile rankings, Chi Square $(3)=2.8, p=.54$.

Research Hypothesis 1.3 proposed that that traditional $(<23)$ medical student age at the time of entry would be related to higher medical school graduation rates and higher academic performance quartile ranking. To test this hypothesis, a Chi-Square analysis was conducted to determine the relationship between age at the time of entry and graduation status $(1=$ age $\leq 23,2=$ age $\geq 24$ by $1=$ graduated, $2=$ not graduated $)$. Age constituted a discrete variable which was nominal in nature. Results of this Chi-Square analysis are reported in Table 5. The Chi-Square analysis did not yield a statistically significant finding between age and two graduate statuses, Chi-Square $(1)=.88, p=.35$.

A second Chi-Square was calculated to investigate the relationship between age at the time of entry and academic performance quartile ranking. This analysis yielded a statistically significant difference among the four quartile ranks and age at the time of entry Chi-Square $(3)=10.03, p=.02$. Results of this Chi-Square analysis are reported in Table 5. Traditionally aged students appear to be more heavily represented in quartile two than their nontraditionally aged peers.

Research Question Two

Research Hypothesis 2.1 proposed that higher cumulative undergraduate GPAs would be related to higher medical school graduation rates and higher academic performance quartile ranking placement. A one way analysis of variance was calculated in which graduation status $(1=$ graduated, $2=$ not graduated $)$ constituted a between group 
variable. Cumulative undergraduate grade point average was a continuous variable that approximated a ratio scale of measurement. Results of this analysis are reported in Table 7. This analysis did not yield a statistically significant finding between the two graduate statuses on the undergraduate cumulative grade point average, $\mathrm{F}(1,248)=.02, p=.90$.

A second one way analysis of variance was calculated in which quartile ranking $(1,2,3$, and 4) constituted a between group variable. Cumulative undergraduate grade point average was a continuous variable that approximated a ratio scale of measurement. Results of this analysis are reported in Table 6 . This analysis yielded a statistically significant difference among the four quartile ranks on the undergraduate grade point average, $F(3,169)=5.65, p=.01$. The Tukey HSD test was used to determine multiple comparisons among the four levels. These Tukey comparisons (Table 6) indicated significantly (a) higher cumulative undergraduate GPA for quartile rank one than rank four $(\mathrm{p}<.05)$, and (b) for quartile rank two than four $(\mathrm{p}<.05)$.

Research Hypothesis 2.2 proposed that higher science undergraduate GPAs would be related to higher graduation rates from medical school and higher academic performance quartile ranking placement. This hypothesis was also tested with a one way analysis of variance in which graduation status $(1=$ graduated, $2=$ not graduated $)$ constituted a between group variable. Undergraduate science GPA, a continuous variable approximated a ratio scale of measurement. Results of this analysis are reported in Table 7. This analysis did not yield a statistically significant finding between the graduation statuses on the undergraduate science grade point average, $\mathrm{F}(1,248)=.28, p=.60$.

A second one way analysis of variance was calculated to test the hypothesis in which quartile ranking, $(1,2,3$, and 4) constituted a between group variable. 
Undergraduate science grade point average was a continuous variable that approximated a ratio scale of measurement. Results of this analysis are reported in Table

7. The analysis yielded a statistically significant difference among the four quartile ranks on the undergraduate science grade point average, $F(3,169)=7.40, p=.01$. The Tukey comparisons (Table 9) indicated significantly (a) higher cumulative undergraduate science GPA for quartile rank one than ranks three and four $(\mathrm{p}<.05)$, and (b) for quartile rank two than four $(\mathrm{p}<.05)$.

Research Hypothesis 2.3 proposed that higher MCAT scores would be related to higher graduation rates from medical school and higher academic performance quartile rankings placement. This hypothesis was tested with a one way analysis of variance in which graduation status $(1=$ graduated, $2=$ not graduated $)$ constituted a between group variable. MCAT scores, a continuous variable, approximated an interval scale of measurement. Results of this analysis are reported in Table 8 . The analysis yielded a statistically significant difference between the two graduation status categories, $F$ (1, $248)=6.53, p=.01$. It also suggested an inverse relationship between higher cumulative MCAT scores and graduation status. Medical student participants with higher cumulative MCAT scores were less likely to graduate.

A second one way analysis of variance was calculated to test this hypothesis in which quartile ranking, $(1,2,3$, and 4$)$ constituted a between group variable. Results of this analysis are reported in Table 8 . This analysis did not yield a statistically significant finding among the four quartile ranks on the MCAT composite score, $\mathrm{F}(3,169)=1.03, p$ $=.38$. A related one way analysis of variance computation on the MCAT biosciences section score, one of five sections of the MCAT, did demonstrate statistically significant 
findings among the quartile ranks $\mathrm{F}(3,169=5.51, p=.01$ The Tukey comparisons indicated significantly (a) MCAT biosciences score for quartile rank two than ranks 3 and four $(p<.05)$. Results of this analysis are reported in Table 9. Significant findings were not demonstrated between MCAT biosciences score and graduation $F(1,246)=1.17, p$ $=2.8$

Research Question Three.

Research Hypothesis 3.1 proposed that lower levels of assessed Extraversion would be related to higher graduation rates and academic performance quartile rankings in medical school. This hypothesis was tested with a one way analysis of variance in which graduation status $(1=$ graduated, $2=$ not graduated $)$ constituted a between group variable. Extraversion global factor raw scores as assessed by the $16 \mathrm{PF}$ were utilized as ratio dependent variables. Results of this analysis are reported in Table 10. The analysis yielded a statistically significant difference between the two graduation status categories assessed extraversion levels $\mathrm{F}(1,226)=6.50 p=.01$.

A second one way analysis of variance was calculated to test this hypothesis in which quartile ranking, $(1,2,3$, and 4$)$ constituted a between group variable and Extraversion global factor raw score as assessed by the 16PF, were utilized as ratio criterion variables. Results of this analysis are reported in Table 10. This analysis did not yield a statistically significant finding among the four quartile ranks and the assessed 16 PF Extraversion score, $\mathrm{F}(3,144)=1.56, p=.20$. Medical student participant with higher levels of Extraversion levels were more likely to graduate than their less extraverted peers. 
Research Hypothesis 3.2 proposed that lower levels of assessed Anxiety would be related to higher graduation rates and academic performance quartile rankings in medical school. This hypothesis was tested with a one way analysis of variance in which graduation status $(1=$ graduated, $2=$ not graduated $)$ constituted a between group variable Anxiety global factor raw scores as assessed by the 16PF were utilized as an interval scale variable. Results of this analysis are reported in Table 11. This analysis yielded a statistically significant difference between the two graduation status categories on the assessed Anxiety levels $F(1,226)=8.13 p=.01$. Medical student participants with lower anxiety levels were more likely to graduate than their more anxious peers.

A second one way analysis of variance was calculated to test this hypothesis in which quartile ranking, $(1,2,3$, and 4$)$ constituted a between group variable and Anxiety global factor raw score as assessed by the $16 \mathrm{PF}$, was utilized as a ratio criterion variable. Results of this analysis are reported in Table 11. This analysis did not yield a statistically significant finding among the four quartile ranks for the assessed 16 PF Anxiety score, F $(3,144)=1.26, p=94$.

Research Hypothesis 3.3 proposed that higher levels of assessed Tough Mindedness would be related to higher graduation rates and academic performance quartile rankings in medical school. This hypothesis also was tested with a one way analysis of variance in which graduation status constituted a between group variable. Tough Mindedness global factor raw score as assessed by the 16PF was utilized as an interval scale variable. Results of this analysis are reported in Table 12. This analysis did not yield a statistically significant difference between the two graduation status categories and the assessed Tough Mindedness levels $F(1,226)=.23 p=.64$. 
A second one way analysis of variance was calculated to test the relationship in which quartile ranking, $(1,2,3$, and 4) constituted a between group variable and the Tough Mindedness global factor raw score as assessed by the 16PF, was utilized as an interval scale variable. Results of this analysis are reported in Table 12. This analysis did not yield a statistically significant finding among the four quartile ranks and the assessed 16 PF Tough Mindedness score, F $(3,144)=2.19, p=.09$.

Research Hypothesis 3.4 proposed that higher levels of assessed Independence would be related to higher graduation rates and academic performance quartile rankings in medical school. This hypothesis also was tested with a one way analysis of variance in which graduation status ( $1=$ graduated, $2=$ not graduated $)$ constituted a between group variable. Independence global factor raw score as assessed by the 16PF was utilized as a interval scale variable. Results of this analysis are reported in Table 13. This analysis did yield a statistically significant difference between the two graduation status categories and the assessed independence levels $F(1,226)=15.51, p=.001$. Medical student participants with higher independence levels were more likely to graduate than their less independent peers.

A second one way analysis of variance was calculated to test this relationship in which quartile ranking, (1, 2, 3, and 4) constituted a between group variable. Independence global factor raw score as assessed by the $16 \mathrm{PF}$, was utilized as an interval scale variable. Results of this analysis are reported in Table 13. This analysis did not yield a statistically significant finding among the four quartile ranks on the assessed 16 PF Independence score, $\mathrm{F}(3,144)=.403, p=.75$. 
Research Hypothesis 3.5 proposed that higher levels of assessed Self Control would be related to higher graduation rates and academic performance quartile rankings in medical school. This hypothesis was also tested with a one way analysis of variance in which graduation status $(1=$ graduated, $2=$ not graduated $)$ constituted a between group variable. Self Control global factor raw score as assessed by the 16PF was utilized as a ratio criterion variable. Results of this analysis are reported in Table 14. This analysis did not yield a statistically significant difference between the two graduation status categories on the assessed Self Control levels $F(1,226)=3.52, p=.06$. This finding, however, did represent a trend in which the not graduated group tended to higher self control levels.

A second one way analysis of variance was calculated to test this relationship in which quartile ranking, $(1,2,3$, and 4$)$ constituted a between group variable and Self Control global factor raw score as assessed by the 16PF was utilized as an interval scale variable. Results of this analysis are reported in Table 14. This analysis did not yield a Self Control score, $\mathrm{F}(3,144)=.58, p=.63$.

Research Hypothesis 3.6 proposed that some of the 16 PF Primary Factors (Warmth, Reasoning , Emotional Stability, Dominance, Liveliness, Rule Consciousness, Social Boldness, Sensitivity, Vigilance, Abstractness, Privateness, Apprehension, Openness to Change, Self Reliance, Perfectionism, and Tension) would be related to higher graduation rates and higher academic performance quartile ranking. This hypothesis was tested with a set of 16 one way analyses of variance in which graduation status $(1=$ graduated, $2=$ not graduated $)$ was the independent variable and the 16 primary factor raw scores as assessed by the $16 \mathrm{PF}$ was utilized as ratio dependent variables. To more fully control for error the significance level was adjusted to 025 . Results of these 
analyses are reported in Tables 15-31. Significant findings were demonstrated for the following 16PF primary factors: Emotional Stability, $F(1,226)=15.08, p=.001$, Dominance, $F(1,226)=15.31, p=.001 .$, Liveliness, $F(1,226)=10.85, p=.001$, Social Boldness, $F(1,226)=13.40, p=.001$, and Apprehension, $F(1,226)=6.04, p=$ .02 .

A second set of one way analyses of variance was calculated to test this hypothesis in which quartile ranking, $(1,2,3$, and 4$)$ constituted a between group variable and the 16 Primary factors global factor raw scores, respectively were utilized as dependant variables. These analyses did not yield a statistically significant difference between the academic quartile ranking categories in any of the 16PF primary factors.

Summary of Results

A summary of the findings is provided in tables in 31- 35 . 
Table 2

Demographics of Participants $n=250$

\begin{tabular}{|c|c|c|}
\hline Variable & Frequency & Percent \\
\hline \multicolumn{3}{|l|}{$\underline{\operatorname{Sex}}$} \\
\hline Male & 155 & 62 \\
\hline Female & 95 & 38 \\
\hline \multicolumn{3}{|l|}{$\underline{\text { Race }}$} \\
\hline African American & 2 & .8 \\
\hline Native American & 1 & .4 \\
\hline Hispanic & 3 & 1.2 \\
\hline Asian & 46 & 18.4 \\
\hline White/Caucasian & 198 & 79.2 \\
\hline Missing & & \\
\hline \multicolumn{3}{|l|}{ Age } \\
\hline Less than 23 & 212 & 85.1 \\
\hline 23 and older & 37 & 14.9 \\
\hline \multicolumn{3}{|l|}{ Graduation Status } \\
\hline$\overline{\text { Graduated }}$ & 221 & 84.4 \\
\hline Did not graduate & 29 & 11.6 \\
\hline \multicolumn{3}{|l|}{ *Quartile Ranking } \\
\hline $1^{\text {st }}$ Quartile & 43 & 25.4 \\
\hline $2^{\text {nd }}$ Quartile & 43 & 24.4 \\
\hline $3^{\text {rd }}$ Quartile & 42 & 24.9 \\
\hline $4^{\text {th }}$ Quartile & 41 & 24.3 \\
\hline \multicolumn{3}{|l|}{16 PF Data $* *$} \\
\hline Available & 144 & 57.6 \\
\hline Not Available & 106 & 42.4 \\
\hline
\end{tabular}

* Available for only 169 participants.

** Available for only 144 participants 
Table 3

Research Hypothesis 1.1 Sex

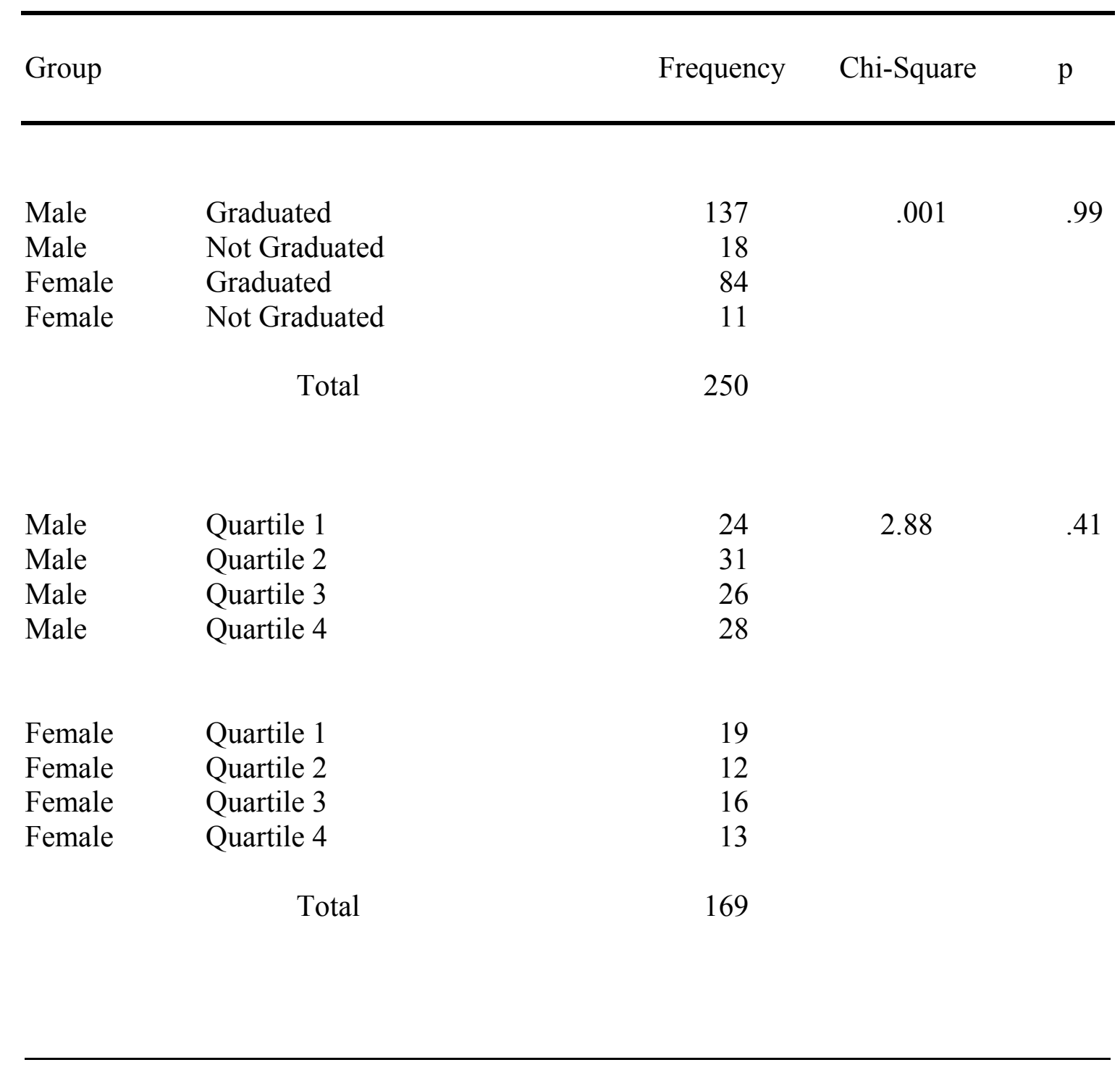

Significance level: $\mathrm{p}=.05$ 
Table 4

Research Hypothesis 1.2 Race

\begin{tabular}{llccr}
\hline Group & & Frequency & Chi-Square & $p$ \\
\hline & & & \\
White/Caucasian & Graduated & 170 & 6.01 & $.01^{* *}$ \\
White/Caucasian & Not Graduated & 28 & &
\end{tabular}

$\begin{array}{llr}\text { All Other Minority } & \text { Graduated } & 51 \\ \text { Participants } & & \\ \begin{array}{c}\text { All Other Minority } \\ \text { Participants }\end{array} & \text { Not Graduated } & 1\end{array}$

Total 250

$\begin{array}{llll}\text { White/Caucasian } & \text { Quartile 1 } & 33 & 2.8 \\ \text { White/Caucasian } & \text { Quartile 2 } & 33 & \\ \text { White/Caucasian } & \text { Quartile 3 } & 35 & \\ \text { White/Caucasian } & \text { Quartile 4 } & 35\end{array}$

$\begin{array}{ll}\text { All Other Minority Quartile 1 } & 10\end{array}$

Participants

All Other Minority Quartile 2 10

Participants

All Other Minority Quartile 3 7

Participants

All Other Minority Quartile 4 6

Participants

Total

Significance level: $\mathrm{p}=.05$

$* *$ indicates results are significant 
Table 5

Research Hypothesis 1.3 Age

\begin{tabular}{lll}
\hline Group & Frequency & Chi-Square $p$ \\
\hline
\end{tabular}

Age $\leq 23 \quad$ Graduated

Age $\leq 23 \quad$ Not Graduated

189

.88

.35

Age $\geq 24 \quad$ Graduated

31

Age $\geq 24 \quad$ Not Graduated

23

6

Total

249

Age $\leq 23 \quad$ Quartile 1

30

10.03

$.02 * *$

Age $\leq 23 \quad$ Quartile 2

42

Age $\leq 23 \quad$ Quartile 3

32

Age $\leq 23 \quad$ Quartile 4

34

Age $\geq 24 \quad$ Quartile 1

13

Age $\geq 24 \quad$ Quartile 2

2

Age $\geq 24 \quad$ Quartile 3

10

Age $\geq 24 \quad$ Quartile 4

Total

169

Significance level: $p=.05$

** indicates results are significant

Quartile ranking data was available for only 169 participants

( $1=$ age $\leq 23,2=\geq 24$ by $1=$ graduated, $2=$ not graduated $)$. 
Table 6

Research Hypothesis 2.1 CGPA

\begin{tabular}{|c|c|c|c|c|c|c|}
\hline \multirow[b]{2}{*}{ Group } & \multicolumn{3}{|c|}{$\begin{array}{c}\text { Undergraduate } \\
\text { Grade Point } \\
\text { Average }\end{array}$} & \multicolumn{3}{|c|}{ ANOVA } \\
\hline & Frequency & Mean & $\mathrm{SD}$ & $\mathrm{df}$ & $\mathrm{F}$ & $\mathrm{p}$ \\
\hline \multicolumn{7}{|l|}{ Graduate status } \\
\hline Graduated & 221 & 3.64 & 4.58 & $(1,248)$ & .02 & .90 \\
\hline Not Graduated & 29 & 3.63 & 4.79 & & & \\
\hline \multicolumn{7}{|l|}{ Quartile Ranking } \\
\hline 1 & 43 & 3.73 & .23 & $(3,165)$ & 5.65 & .01 \\
\hline 2 & 43 & 3.70 & .22 & & & $* *$ \\
\hline 3 & 42 & 3.61 & .26 & & & \\
\hline 4 & 41 & 3.53 & .27 & & & \\
\hline
\end{tabular}

Tukey HSD Multiple Comparisons

Quartile 1 $>4 \quad \mathrm{p}=.002$

Quartile 2>4 $\mathrm{p}=.001$

Significance level: $\mathrm{p}=.05$

** indicates results are significant

Quartile ranking data was available for only 169 participants 
Table 7

Research Hypothesis 2.2 SGPA

\begin{tabular}{|c|c|c|c|c|c|c|}
\hline \multirow[b]{2}{*}{ Group } & \multicolumn{3}{|c|}{$\begin{array}{r}\text { Undergraduate } \\
\text { Science GPA }\end{array}$} & \multicolumn{3}{|c|}{ ANOVA } \\
\hline & Frequency & Mean & SD & df & $\mathrm{F}$ & $\mathrm{p}$ \\
\hline \multicolumn{7}{|l|}{ Graduate status } \\
\hline Graduated & 221 & 3.56 & .31 & $(1,248)$ & .28 & .60 \\
\hline Not Graduated & 29 & 3.60 & .30 & & & \\
\hline \multicolumn{7}{|l|}{ Quartile Ranking } \\
\hline 1 & 43 & 3.70 & .26 & $(3,165)$ & 7.40 & $.01 * *$ \\
\hline 2 & 43 & 3.67 & .26 & & & \\
\hline 3 & 42 & 3.53 & .32 & & & \\
\hline 4 & 41 & 3.42 & .34 & & & \\
\hline
\end{tabular}

Tukey HSD Multiple Comparisons

Quartile 1>3 $\quad \mathrm{p}=.05$

Quartile $1>4 \quad \mathrm{p}=.05$

Quartile 2 $>4 \quad \mathrm{p}=.05$

Significance level: $\mathrm{p}=.05 \%$

** indicates results are significant

Quartile ranking data was available for only 169 participants 
Table 8

Research Hypothesis 2.3 MCAT

Cumulative

MCAT Score
ANOVA

Group

Frequency

Mean

SD

df

$\mathrm{F} \quad \mathrm{p}$

Graduate status

Graduated

Not Graduated

221

29

32.38

34.41

3.95

4.50

$(1,248)$

$6.53 .01 * *$

Quartile Ranking

\begin{tabular}{|c|c|c|c|c|}
\hline 1 & 43 & 32.79 & 4.51 & $(3,165)$ \\
\hline 2 & 43 & 33.26 & 3.78 & \\
\hline 3 & 42 & 32.60 & 3.45 & \\
\hline 4 & 41 & 31.73 & 4.43 & \\
\hline
\end{tabular}

Significance level: $\mathrm{p}=.05$

** indicates results are significant

Quartile ranking data was available for only 169 participants 
Table 9

Research Hypothesis 2.3 MCAT Biosciences

\begin{tabular}{|c|c|c|c|c|c|c|}
\hline \multirow[b]{2}{*}{ Group } & & $\begin{array}{l}\text { MCAT } \\
\text { oscien } \\
\text { Scores }\end{array}$ & & \multicolumn{3}{|c|}{ ANOVA } \\
\hline & Frequency & Mean & SD & $\mathrm{df}$ & $\mathrm{F}$ & $\mathrm{p}$ \\
\hline \multicolumn{7}{|l|}{ Graduate status } \\
\hline Graduated & 219 & 9.16 & 1.38 & $(1,246)$ & 1.17 & .28 \\
\hline Not Graduated & 29 & 9.45 & 1.33 & & & \\
\hline \multicolumn{7}{|l|}{ Quartile Ranking } \\
\hline 1 & 43 & 9.16 & 1.63 & $(3,163)$ & 5.51 & .001 \\
\hline 2 & 43 & 9.74 & 1.27 & & & ** \\
\hline 3 & 41 & 8.68 & .99 & & & \\
\hline 4 & 40 & 8.80 & 1.29 & & & \\
\hline
\end{tabular}

Tukey HSD Multiple Comparisons

Quartile 2 $>3 \quad \mathrm{p}=.002$

Quartile 2>4 $\quad \mathrm{p}=.007$

Significance level: $\mathrm{p}=.05$

** indicates results are significant

Quartile ranking data was available for only 169 participants 
Table 10

Research Hypothesis 3.1 Evtraversion

Extraversion

Raw Scores
ANOVA

Group

Mean

SD

df

F

$\mathrm{p}$

Graduate status

Graduated

$217^{*} \quad 60.66 \quad 18.89$

$11 * \quad 45.64 \quad 19.66$

$(1,226)$

$6.50 \quad .01 * *$

Not Graduated

19.66

Quartile Ranking

$\begin{array}{llllllll}1 & 38 & 54.11 & 19.93 & (3,144) & 1.56 & .20 \\ 2 & 36 & 63.08 & 17.76 & & & & \\ 3 & 36 & 59.56 & 20.60 & & & \\ 4 & 38 & 55.82 & 19.47 & & & \end{array}$

Significance level: $\mathrm{p}=.05$

** indicates results are significant

* 16 PF was only available for 228 research participants 
Table 11

Research Hypothesis 3.2 Anxiety

\begin{tabular}{ccccccc}
\hline & \multicolumn{2}{c}{ Anxiety Raw } & & \\
Score & & & \\
& & & & \\
& & & & \\
Group & Frequency & Mean & SD & df & F & $\mathrm{p}$ \\
\hline
\end{tabular}

Graduate status

Graduated

Not Graduated

$\begin{array}{rrr}217 * & 52.61 & 17.79 \\ 11 * & 68.36 & 19.52\end{array}$

$(1,226)$

$8.13 .01 * *$

Quartile Ranking

$\begin{array}{llllllll}1 & 38 & 56.71 & 18.48 & (3,144) & 1.26 & .94 \\ 2 & 36 & 54.80 & 18.24 & & & & \\ 3 & 36 & 54.08 & 19.70 & & & \\ 4 & 38 & 54.89 & 20.45 & & & & \end{array}$

Significance level: $\mathrm{p}=.05$

** indicates results are significant

* 16 PF was only available for 228 research participants 
Table 12

Research Hypothesis 3.3 Tough-Mindedness

\begin{tabular}{|c|c|c|c|c|c|c|}
\hline \multirow[b]{2}{*}{ Group } & \multicolumn{3}{|c|}{ Tough-Mindedness } & \multicolumn{3}{|c|}{ ANOVA } \\
\hline & Frequency & Mean & $\mathrm{SD}$ & $\mathrm{df}$ & $\mathrm{F}$ & $\mathrm{p}$ \\
\hline
\end{tabular}

Graduate status

Graduated

$217 * \quad 52.91 \quad 20.25$

$(1,226)$

$.23 \quad .64$

Not Graduated

$11^{*} \quad 55.91 \quad 23.74$

Quartile Ranking

$\begin{array}{lllllll}1 & 38 & 57.24 & 17.68 & (3,144) & 2.19 & .09 \\ 2 & 36 & 59.31 & 19.37 & & & \\ 3 & 36 & 48.08 & 19.41 & & & \\ 4 & 38 & 54.21 & 22.62 & & & \end{array}$

Significance level: $\mathrm{p}=.05$

* 16 PF was only available for 228 research participants 
Table 13

Research Hypothesis 3.4 Independence

\begin{tabular}{ccccccc}
\hline & \multicolumn{2}{c}{$\begin{array}{c}\text { Independence } \\
\text { Raw Score }\end{array}$} & & \multicolumn{2}{c}{ ANOVA } \\
Group & Frequency & Mean & SD & df & F & p \\
\hline
\end{tabular}

Graduate status

Graduated

$217^{*} \quad 60.66 \quad 18.81$

$45.60 \quad 13.81$

$(1,226) \quad 15.51 .001 * *$

Not Graduated

$11 * \quad 45.60 \quad 13.81$

Quartile Ranking

$\begin{array}{lllllll}1 & 38 & 55.001 & 19.73 & (3,144) & .403 & .75 \\ 2 & 36 & 49.48 & 17.01 & & & \\ 3 & 36 & 52.28 & 17.91 & & & \\ 4 & 38 & 52.42 & 17.06 & & & \end{array}$

Significance level: $\mathrm{p}=.05$

** indicates results are significant

* 16 PF was only available for 228 research participants 
Table 14

Research Hypothesis 3.5 Self-Control

\begin{tabular}{lcccccc}
\hline & \multicolumn{2}{c}{$\begin{array}{c}\text { Self-Control } \\
\text { Raw Score }\end{array}$} & & ANOVA \\
Group & Frequency & Mean & SD & df & F & p \\
\hline
\end{tabular}

Graduate status

Graduated

$217^{*} \quad 50.35 \quad 17.18$

$(1,226)$

$3.52 .06^{* *}$

Not Graduated

$11^{*} \quad 60.36 \quad 19.06$

Quartile Ranking

$\begin{array}{llllllll}1 & 38 & 55.001 & 19.73 & & (3,144) & .58 & .63 \\ 2 & 36 & 49.47 & 17.01 & & & & \\ 3 & 36 & 52.28 & 17.91 & & & \\ 4 & 38 & 52.42 & 17.06 & & & & \end{array}$

Significance level: $\mathrm{p}=.05$

* 16 PF was only available for 228 research participants

** represents a trend 


\section{Table 15}

Research Hypothesis 3.6 Warmth

$$
\begin{gathered}
\text { Warmth } \\
\text { Raw Score }
\end{gathered}
$$

ANOVA

Group

Graduate status

Graduated

Not Graduated

$\begin{array}{rrr}217^{*} & 14.32 & 4.29 \\ 11 * & 13.58 & 4.87\end{array}$

$(1,226)$

$.33 \quad .57$

Frequency

Mean

SD

df

\section{F}

$\mathrm{p}$

Quartile Ranking

$\begin{array}{llllllll}1 & 38 & 13.33 & 4.54 & (3,144) & .76 & .52 \\ 2 & 36 & 14.39 & 4.08 & & & & \\ 3 & 36 & 14.61 & 4.13 & & & \\ 4 & 38 & 13.58 & 4.56 & & & & \end{array}$

Significance level: $\mathrm{p}=.025$

** indicates results are significant

* 16 PF was only available for 228 research participants 
Table 16

Research Hypothesis 3.6 Reasoning

\begin{tabular}{ccccccc}
\hline & \multicolumn{2}{c}{ Reasoning } & & & \\
& Raw Score & & & \\
& & & & \\
Group & Frequency & Mean & SD & df & F & p \\
\hline
\end{tabular}

Graduate status

Graduated

$217 * \quad 12.72 \quad 1.61$

$(1,226) \quad .03 \quad .86$

Not Graduated

$11 * \quad 12.67 \quad 2.20$

Quartile Ranking

$\begin{array}{llllllll}1 & 38 & 12.61 & 1.78 & (3,144) & .36 & .78 \\ 2 & 36 & 12.83 & 1.65 & & & \\ 3 & 36 & 12.80 & 1.65 & & & \\ 4 & 38 & 12.50 & 1.39 & & & & \end{array}$

Significance level: $\mathrm{p}=.025$

* 16 PF was only available for 228 research participants 
Table 17

Research Hypothesis 3.6 Emotional Stability

\begin{tabular}{|c|c|c|c|c|c|c|}
\hline \multirow[b]{2}{*}{ Group } & \multicolumn{3}{|c|}{$\begin{array}{c}\text { Emotional } \\
\text { Stability } \\
\text { Raw Score }\end{array}$} & \multicolumn{3}{|c|}{ ANOVA } \\
\hline & Frequency & Mean & $\mathrm{SD}$ & $\mathrm{df}$ & $\mathrm{F}$ & $\mathrm{p}$ \\
\hline \multicolumn{7}{|l|}{ Graduate status } \\
\hline Graduated & $217^{*}$ & 15.49 & 4.10 & $(1,226)$ & 15.08 & .001 \\
\hline Not Graduated & $11 *$ & 10.55 & 4.58 & & & \\
\hline \multicolumn{7}{|l|}{ Quartile Ranking } \\
\hline 1 & 38 & 14.95 & 4.36 & $(3,144)$ & .34 & .80 \\
\hline 2 & 36 & 15.17 & 4.47 & & & \\
\hline 3 & 36 & 14.17 & 5.29 & & & \\
\hline 4 & 38 & 14.95 & 4.08 & & & \\
\hline
\end{tabular}

Significance level: $p=.025$

$* *$ indicates results are significant

* 16 PF was only available for 228 research participants 
Table 18

Research Hypothesis 3.6 Dominance

\begin{tabular}{|c|c|c|c|c|c|}
\hline \multirow[b]{2}{*}{ Group } & \multicolumn{3}{|c|}{ Dominance } & \multicolumn{2}{|c|}{ ANOVA } \\
\hline & Frequency & Mean & $\mathrm{SD}$ & $\mathrm{df}$ & $\mathrm{F}$ \\
\hline
\end{tabular}

Graduate status

Graduated

$217 *$

$13.14 \quad 4.03$

$8.27 \quad 3.98$

$(1,226) \quad .001 * *$

Not Graduated

$11 *$

3.98

Quartile Ranking

\begin{tabular}{|c|c|c|c|c|c|}
\hline 1 & 38 & 12.50 & 4.61 & $(3,144)$ & .18 \\
\hline 2 & 36 & 12.42 & 4.21 & & \\
\hline 3 & 36 & 13.001 & 4.05 & & \\
\hline 4 & 38 & 2.95 & 4.36 & & \\
\hline
\end{tabular}

Significance level: $\mathrm{p}=.025$

$* *$ indicates results are significant

* 16 PF was only available for 228 research participants 
Table 19

Research Hypothesis 3.6 Liveliness

\begin{tabular}{cccccc}
\hline & \multicolumn{2}{c}{ Liveliness } & & \\
Raw Score & & & ANOVA \\
Group & Frequency & Mean & SD & df & F \\
\hline
\end{tabular}

Graduate status

Graduated

$217^{*} \quad 14.27 \quad 4.45$

$9.73 \quad 4.84$

$(1,226) \quad 10.85 .001 * *$

Not Graduated

$11^{*}$

4.84

$(1,226)$

Quartile Ranking

$\begin{array}{llllllll}1 & 38 & 12.50 & 4.88 & (3,144) & 1.13 & .33 \\ 2 & 36 & 14.42 & 4.04 & & & \\ 3 & 36 & 13.72 & 4.96 & & & \\ 4 & 38 & 13.29 & 4.41 & & & \end{array}$

Significance level: $\mathrm{p}=.025$

** indicates results are significant

* 16 PF was only available for 228 research participants 
Table 20

Research Hypothesis 3.6 Role Consciousness

\begin{tabular}{ccccccc}
\hline & \multicolumn{2}{c}{ Role Consciousness } & & & \\
Raw Score & & & \\
& & & & \\
Group & Frequency & Mean & SD & df & F & p \\
\hline
\end{tabular}

Graduate status

Graduated

$217^{*} \quad 13.80 \quad 4.80$

$(1,226)$

$.65 \quad .42$

Not Graduated

$11 *$

15.00

5.04

Quartile Ranking

$\begin{array}{llllllll}1 & 38 & 14.42 & 5.11 & (3,144) & 1.94 & .13 \\ 2 & 36 & 12.33 & 4.84 & & & & \\ 3 & 36 & 14.81 & 4.86 & & & \\ 4 & 38 & 14.29 & 4.27 & & & \end{array}$

** Significance level: $\mathrm{p}=.025$

* 16 PF was only available for 228 research participants 
Table 21

Research Hypothesis 3.6 Social Boldness

\begin{tabular}{ccccccc}
\hline & \multicolumn{2}{c}{ Social Boldness } & & & \\
Raw Score & & & \\
& & & & \\
Group & Frequency & Mean & SD & df & F & p \\
\hline
\end{tabular}

Graduate status

Graduated

$217 * \quad 10.84 \quad 6.80$

$3.27 \quad 3.75$

$(1,226) \quad 13.40 .001 * *$

Not Graduated

$11^{*}$

(1)

Quartile Ranking

$\begin{array}{lrrrrrr}1 & 38 & 10.26 & 7.12 & (3,144) & .52 & .67 \\ 2 & 36 & 10.92 & 6.91 & & & \\ 3 & 36 & 11.31 & 6.19 & & \\ 4 & 38 & 9.47 & 6.81 & & \end{array}$

Significance level: $\mathrm{p}=.025 * *$ indicates results are significant

* 16 PF was only available for 228 research participants 
Table 22

Research Hypothesis 3.6 Sensitivity

\begin{tabular}{llllll}
\hline & \multicolumn{2}{c}{ Sensitivity } & & \\
Raw Score & & & ANOVA \\
Group & Frequency & Mean & SD & df & F \\
\hline
\end{tabular}

Graduate status

Graduated

$217^{*} \quad 10.63 \quad 6.001$

$(1,226) \quad .60 \quad .44$

Not Graduated

$11 * \quad 12.09 \quad 7.27$

Quartile Ranking

$\begin{array}{lrrrrrrr}1 & 38 & 10.71 & 5.49 & (3,144) & 1.68 & .17 \\ 2 & 36 & 9.11 & 6.10 & & & & \\ 3 & 36 & 12.19 & 5.46 & & & \\ 4 & 38 & 10.29 & 6.49 & & & \end{array}$

Significance level: $\mathrm{p}=.025$

* 16 PF was only available for 228 research participants 
Table 23

Research Hypothesis 3.6 Vigilance

\begin{tabular}{ccccccc}
\hline & \multicolumn{2}{c}{ Vigilance } & & & \multicolumn{2}{c}{ ANOVA } \\
& Raw Score & & & & \\
Group & Frequency & Mean & SD & df & F & p \\
\hline
\end{tabular}

Graduate status

Graduated

$217 * \quad 11.63 \quad 4.15$

$12.36 \quad 3.67$

$(1,226)$

$.33 \quad .57$

Not Graduated

$11 *$

$\begin{array}{llllllll}1 & 38 & 12.37 & 3.50 & (3,144) & 1.04 & .38 \\ 2 & 36 & 12.36 & 4.56 & & & \\ 3 & 36 & 10.97 & 4.38 & & & \\ 4 & 38 & 11.34 & 4.50 & & & \end{array}$

$(3,144) \quad 1.04 \quad .38$

Quartile Ranking

Significance level: $\mathrm{p}=.025$

* 16 PF was only available for 228 research participants 
Table 24

Research Hypothesis 3.6 Abstractness

\begin{tabular}{ccccccc}
\hline & \multicolumn{2}{c}{$\begin{array}{c}\text { Abstractness } \\
\text { Raw Score }\end{array}$} & & ANOVA \\
Group & Frequency & Mean & SD & df & F & p \\
\hline
\end{tabular}

Graduate status

$\begin{array}{ccccccc}\text { Graduated } & 217^{*} & 8.76 & 5.51 & (1,226) & 1.52 & .22 \\ \text { Not Graduated } & 11 & 6.64 & 6.09 & & & \\ & & & & & & \\ \text { Quartile Ranking } & & & & & & \\ 1 & 38^{*} & 7.84 & 5.78 & (3,144) & .28 & .84 \\ 2 & 36 & 8.28 & 5.92 & & & \\ 3 & 36 & 9.001 & 5.88 & & \\ 4 & 38 & 8.71 & 5.77 & \end{array}$

Quartile Ranking

Significance level: $p=.025$ 
Table 25

Research Hypothesis 3.6 Privateness

\begin{tabular}{ccccccc}
\hline & \multicolumn{2}{c}{ Privateness } & & \multicolumn{2}{c}{ ANOVA } \\
& Raw Score & & & & \\
Group & & & & & & \\
\hline
\end{tabular}

Graduate status

Graduated

Not Graduated

$\begin{array}{rll}217^{*} & 10.59 & 5.66 \\ 11^{*} & 13.001 & 4.94\end{array}$

$(1,226)$

1.92

.17

Quartile Ranking

$\begin{array}{lrrrrrr}1 & 38 & 12.03 & 6.13 & (3,144) & 2.21 & .09 \\ 2 & 36 & 9.11 & 5.85 & & & \\ 3 & 36 & 10.61 & 5.29 & & & \\ 4 & 38 & 12.05 & 5.50 & & & \end{array}$

Significance level: $\mathrm{p}=.025$

* 16 PF was only available for 228 research participants 
Table 26

Research Hypothesis 3.6 Apprehension

\begin{tabular}{ccccccr}
\hline & \multicolumn{2}{c}{ Apprehension } & & & \\
& Raw Score & & & \\
& & & & \\
Group & Frequency & Mean & SD & df & F & p \\
\hline
\end{tabular}

Graduate status

Graduated

Not Graduated

$\begin{array}{rrr}217^{*} & 12.79 & 5.01 \\ 11 * & 16.55 & 2.88\end{array}$

$(1,226)$

$6.04 .02 * *$

Not Graduated

$16.55-2.88$

Quartile Ranking

$\begin{array}{lllllll}1 & 38 & 13.89 & 5.39 & (3,144) & .52 & .67 \\ 2 & 36 & 12.72 & 4.95 & & & \\ 3 & 36 & 12.69 & 4.95 & & \\ 4 & 38 & 13.53 & 4.86 & & \end{array}$

Significance level: $\mathrm{p}=.025$

$* *$ indicates results are significant

* 16 PF was only available for 228 research participants 
Table 27

Research Hypothesis 3.6 Openness to Change

\begin{tabular}{ccccccc}
\hline & \multicolumn{2}{c}{ Openness to } & & & \\
Change & & & ANOVA \\
Raw Score & & & & \\
Group & Frequency Mean & SD & df & F & p \\
\hline
\end{tabular}

Graduate status

Graduated

$217 * \quad 19.31 \quad 5.35$

$17.01 \quad 6.03$

$(1,226)$

1.93

.17

Not Graduated

$11 *$

6.03

Quartile Ranking

$\begin{array}{llllllll}1 & 38 & 18.13 & 5.04 & (3,144) & 1.34 & .27 \\ 2 & 36 & 17.36 & 5.47 & & & \\ 3 & 36 & 19.78 & 6.27 & & & \\ 4 & 38 & 19.16 & 5.54 & & & & \end{array}$

Significance level: $\mathrm{p}=.025$

* 16 PF was only available for 228 research participants 
Table 28

Research Hypothesis 3.6 Self-Reliance

\begin{tabular}{ccccccc}
\hline & \multicolumn{2}{c}{$\begin{array}{c}\text { Self-Reliance } \\
\text { Raw Score }\end{array}$} & & \multicolumn{2}{c}{ ANOVA } \\
Group & Frequency & Mean & SD & df & F & p \\
\hline
\end{tabular}

Graduate status

Graduated

$217^{*} \quad 7.06 \quad 4.79$

4.79
6.61

$(1,226)$

$4.8 \quad .03$

Not Graduated

$11^{*} \quad 10.36 \quad 6.61$

Quartile Ranking

$\begin{array}{llllllll}1 & 38 & 8.47 & 4.94 & (3,144) & .98 & .41 \\ 2 & 36 & 6.58 & 4.84 & & & & \\ 3 & 36 & 8.15 & 5.52 & & & \\ 4 & 38 & 7.58 & 4.92 & & & \end{array}$

Significance level: $\mathrm{p}=.025$

* 16 PF was only available for 228 research participants 
Table 29

Research Hypothesis 3.6 Perfectionism

\begin{tabular}{cccccccc}
\hline & \multicolumn{2}{c}{$\begin{array}{c}\text { Perfectionism } \\
\text { Raw Scores }\end{array}$} & & & & & \\
GNOVA & & & \\
Group & Frequency & Mean & SD & df & F & p \\
\hline Graduate status & & & & & & \\
Graduated & $217^{*}$ & 11.38 & 5.23 & $(1,226)$ & 1.48 & .23 \\
Not Graduated & $11^{*}$ & 13.36 & 6.09 & & & \\
& & & & & & \\
& & & & & & \\
Quartile Ranking & & & & & & \\
1 & 38 & 12.32 & 5.32 & & & \\
2 & 36 & 11.50 & 5.37 & & & \\
3 & 36 & 11.64 & 5.09 & & &
\end{tabular}

Significance level: $\mathrm{p}=.025$

* 16 PF was only available for 228 research participants 
Table 30

Research Hypothesis 3.6 Tension

\begin{tabular}{ccccccc}
\hline & \multicolumn{2}{c}{ Tension } & & \multicolumn{2}{c}{ ANOVA } \\
& Raw Score & & & & \\
Group & Frequency & Mean & SD & df & F & p \\
\hline
\end{tabular}

Graduate status

Graduated

$217^{*} \quad 10.62 \quad 4.61$

$\begin{array}{lll}(1,226) \quad & 1.05 \quad .31\end{array}$

Not Graduated

$11^{*}$

12.09

5.59

Quartile Ranking

$\begin{array}{lllllll}1 & 38 & 11.11 & 5.04 & (3,144) & .17 & .92 \\ 2 & 36 & 11.06 & 4.98 & & & \\ 3 & 36 & 10.72 & 4.70 & & & \\ 4 & 38 & 11.13 & 4.79 & & & \end{array}$

Significance level: $p=.025$

* 16 PF was only available for 228 research participants 
Table 31

Findings for Research Question's 1-3

Primary

Factors

Sex

Race

Age

Sex

\section{Cognitive}

Factors

CGPA

SGPA

MCAT

Global

Factors

Extraversion

Anxiety

Tough

Mindedness

Independence

Self Control

\section{Graduation Status}

Chi-Square $(1)=0.0, p=.99$.

Chi-Square $(1)=.81, p=.01$

Chi-Square $(1)=.88, p=.35$.

Chi-Square $(1)=0.0, p=.99$.

\section{Quartile Ranking}

Chi-Square $(3)=2.88, p=.41$.

Chi Square $(3)=2.8, p=.54$

Chi-Square $(3)=10.03, \mathrm{p}=.02$.

Chi-Square $(3)=2.88, p=.41$.
$\mathrm{F}(1,248)=.02, p=.90$.

$\mathrm{F}(1,248)=.28, p=.60$.

$F(1,248)=6.53, p=.01$

$\mathrm{F}(1,226)=6.50 p=.01$.

$F(1,226)=8.13 p=.01$

$F(1,226)=.23 p=.64$

$F(1,226)=15.51, p=.001$

$F(1,226)=3.52, p=.06$
$\mathrm{F}(3,144)=1.56, p=.20$

$(3,144)=1.26, p=94$

$\mathrm{F}(3,144)=2.19, p=.09$

$\mathrm{F}(3,144)=.403, p=.75$.

$\mathrm{F}(3,144)=.58, p=.63$ 
Table 31 (cont.)

Findings for Research Question's 1-3

\begin{tabular}{|c|c|c|}
\hline $\begin{array}{l}\text { Primary } \\
\text { Factors }\end{array}$ & Graduation Status & Quartile Ranking \\
\hline Warmth & $F(1,226)=13.58, \mathrm{p}=.57$ & $F(3,144)=.756, p=.521$ \\
\hline Reasoning & $F(1,226)=12.72, p=.86$ & $F(3,144)=.362, p=.781$ \\
\hline Emotional & $F(1,226)=15.08, p=.001$ & $\mathrm{~F}(3,144)=.335, \mathrm{p}=.800$ \\
\hline Dominance & $F(1,226)=15.31, p=.001$ & $\mathrm{~F}(3,144)=.178, \mathrm{p}=.991$ \\
\hline Liveliness & $F(1,226)=10.85, p=.001$ & $F(3,144)=1.133, p=.338$ \\
\hline $\begin{array}{l}\text { Rule } \\
\text { Consciousness }\end{array}$ & $F(1,226)=13.80, \mathrm{p}=.42$ & $F(3,144)=1.945, p=.125$ \\
\hline Social Boldness & $F(1,226)=13.40, p=.001$ & $F(3,144)=.521, p=.669$ \\
\hline Sensitivity & $F(1,226)=10.63, \mathrm{p}=.44$ & $F(3,144)=1.678, p=.174$ \\
\hline Vigilance & $F(1,226)=11.63, \mathrm{p}=.57$ & $F(3,144)=1.035, p=.379$ \\
\hline Abstractness & $F(1,226)=8.76, p=.22$ & $\mathrm{~F}(3,144)=.280, \mathrm{p}=.840$ \\
\hline Privateness & $F(1,226)=10.59, \mathrm{p}=.170$ & $F(3,144)=2.211, p=.089$ \\
\hline Apprehension & $F(1,226)=6.04, p=.02$ & $F(3,144)=.521, p=.668$ \\
\hline $\begin{array}{l}\text { Openness to } \\
\text { Change }\end{array}$ & $F(1,226)=19.31, \mathrm{p}=.17$ & $\mathrm{~F}(3,144)=1.337, \mathrm{p}=.265$ \\
\hline Self Reliance & $F(1,226)=7.06, p=.03$ & $F(3,144)=.978, p=.405$ \\
\hline Perfectionism & $F(1,226)=10.68, p=.26$ & $\mathrm{~F}(3,144)=.171, \mathrm{p}=.916$ \\
\hline Tension & $F(1,226)=10.62, \mathrm{p}=. .31$ & $\mathrm{~F}(3,144)=.191, \mathrm{p}=$ \\
\hline
\end{tabular}




\section{CHAPTER 4}

\section{DISCUSSION}

The primary purpose of this study was to determine if specific personality traits and/or trait patterns, undergraduate GPA (cumulative and science), MCAT scores, and medical student demographics were correlated with success (or lack thereof) in medical school. The findings of this study support a number of the proposed hypotheses, lend support to some prior research, and shed light on new directions for research.

The findings of this study revealed that the identified demographic descriptors (i.e. sex, minority status, and a traditional student age of less than 23 years) were not related to higher graduation rates. Sex and minority status were also not related to higher quartile ranking, in contrast to traditional age, which was related to higher quartile ranking.

This study also examined the relationship between cognitive factors (CGPA, SGPA, MCAT cumulative score) and graduation rates and quartile rankings. Findings revealed that higher CGPA, SGPA, and MCAT cumulative scores were not related to higher graduation rates. In fact, higher MCAT scores appeared to be inversely correlated with graduation rates. Higher CGPA and SGPA were found to be related to higher quartile rankings. Students in the upper graduation quartiles tended to have higher undergraduate CGPA and SGPA. Students with higher MCAT scores, however, were not more likely to achieve higher quartile rankings.

Both the Primary and Global factors of the $16 \mathrm{PF}$ have mixed results relative to their relationships with medical student participant graduation rates and quartile ranking. It is important to note that a low sample size confounds these results, so they must be 
interpreted cautiously. Lower levels among the medical student participants of the Global Factors, Extraversion, and Anxiety, and higher levels of Independence were related to higher graduation rates. Relationships between individuals reporting higher levels of Tough Mindedness and Self Control and their resulting graduation did not appear to exist in this study. That is, students who had higher levels of tough mindedness and self control did not appear to graduate at higher rates. None of the Global Factors (Extraversion, Anxiety, Tough Mindedness, Independence and Self Control) were related to higher quartile ranking. Five of the Primary Factors (Emotional Stability, Dominance, Liveliness, Social Boldness, and Apprehension appeared to be related to higher graduation rates. These and related findings are discussed in the pages which follow.

\section{Demographic Relationship to Performance and Rankings}

It was hypothesized that sex, minority status, and age would be related to graduation rates and performance quartile rankings (Cariaga-Lo et al., 1996; Feil, Kristian, \& Mitchell, 1998; Fitzpatrick \& Wright, 1995; Huxam, et al., 1989; Ramsbottom-Lucier, Johnson, \& Elam, 1995; Tekian, 1998). The findings of this study suggest that student sex, and traditional student age (less than 23 years of age) were not related to higher graduation rates. The findings also suggest that sex and minority status were not related to higher quartile ranking. Given the small size and homogeneity of the sample,(particularly in regards to race) these findings are not surprising. They are also consistent with those of other researchers who failed to find relationships between academic performance and sex (Green, Peter \& Webster, 1991; Peng, Khaw, \& Edariah, 1995), minority status (Peng, Khaw, \& Edariah), and age (Green, Peter \& Webster; Simpson \& Budd, 1996). Another plausible and potentially proactive explanation for 
these findings is the growing presence of formal and informal academic and personal support services, and ongoing efforts to diversify the faculty. These efforts may be mitigating the impact of the climate and contextual barriers experienced by female, minority as well as non-traditionally aged medical students. Research which examines the relationship between utilization of support mechanisms (mentoring, counseling, tutoring, etc.) and academic performance across gender, race and age is warranted. Given these results, and the development of these supports, studies of this kind may enable school of medicine faculty to better evaluate the impact of these supports on medical student performance across race, gender, and age.

In the current study, traditional student age was related to higher quartile ranking among medical student participants. These results must be considered exploratory given the small sample size. Other research fails to support these findings, suggesting that nontraditionally aged students tend to have lower GPA's (Ramsbottom-Lucier, Johnson, \& Elam, 1995; Green, Peter, \& Webster, 1991). This research suggests that the academic performance of older students may be negatively impacted by multiple role demands, learning gaps, less familiarity with prerequisite content, and, in some instances, difficulty accessing and making use of informal support systems which are geared toward traditionally aged students. The findings of this prior research regarding nontraditional medical students should be interpreted and applied cautiously as they may inadvertently impact the evaluation of non-traditionally aged students.

Non-traditionally aged medical students may also bring a higher level of maturity as well as skill sets developed by additional employment and educational experiences which their younger counterparts may lack. Admission committees and academic support 
staff would do well to consider these variables as they evaluate applicants and develop support systems for students.

Cognitive Factors Relationship to Performance and Rankings

It was hypothesized that undergraduate cumulative and science GPAs and MCAT cumulative scores achieved prior to acceptance to medical school were related to graduation rates and academic performance quartile rankings (Cariaga-Lo et al., 1997; Chan-Ob \& Boonyanaruthee, 1999; Claap \& Reid, 1976; Green et al., 1993; Hall \& Bailey, 1992; Koenig et al.; Kutalunga-Moruzi, \& Norman, 2002a, 2002b; Sarnacki, 1982; Mitchell et al., 1994; Shen \& Comrey, 1997; Swanson et al., 1996; Simpson \& Budd, 1996; Webb et al., 1997; Wiley \& Koenig 1996). Findings of the current study revealed that higher CGPA, SGPA, and cumulative MCAT score were not related to higher graduation rates. In fact, higher MCAT composite scores appeared to be inversely correlated with graduation rates. These findings were unexpected considering the volume of literature suggesting moderate to strong correlations between undergraduate GPAs, MCAT composite scores, and academic performance in medical school. A further review of available literature sheds little light on the inverse relationship between MCAT composite scores and graduation rates found in the current study. Research by Shen and Comrey (1997) and Kulatunga-Moruzi and Norman (2001) suggest that, despite the high predictive value of the MCAT, its predictive utility drops sharply when clinical performance is considered. The MCAT may be more reflective of content knowledge and related skills, which are more heavily required in years one and two, typically the basic science years. 
The relationship between cognitive measures like the MCAT and clinical performance seems less clear. Glaser, Hojat, Veloskil, Blacklow and Goep (1992) suggest that although the predictive utility of the composite MCAT appears low for the clinical years, the MCAT Verbal subtest scores and nonscience GPAs are more closely associated with clinical year performance. Because the present study considers medical school performance covering both basic science and clinical years (i.e. graduation rates), the lack of significant findings correlating composite MCAT scores with graduation rates and quartile rankings seems plausible.

Contextual reasons may also provide clues to the inverse relationship found in the present study for composite MCAT scores and graduation rates. For example, the small sample size, emphasis on performance during the clinical years, changes in the curriculum, and grade inflation during the clinical years could all impact the findings of this study. Additionally, one may hypothesize that the MCAT composite score does not adequately measure the skills required for achieving academic success at this institution. Given this possibility, the selection process of medical students should utilize a broad range of applicant variables in the evaluation process. Future research which examines the relationship between MCAT composite and subtest scores and performance during both the basic science and clinical years (as separate variables) would shed light on these issues.

The present study also found that higher CGPA and SGPA were not related to higher graduation rates. Although GPA is frequently utilized in the selection process for admission of medical students (Hall \& Bailey, 1992; Jones \& Thomas-Forques, 1984; Mitchell, Haynes, \& Koenig, 1994), it is typically less robustly correlated with academic 
success in medical school (Shen \& Comrey, 1997; Sarnacki, 1982). Both Sarnacki and Comrey suggest that undergraduate GPA is influenced by a number of factors involving discrepancies in the various undergraduate institutions, including, among other factors: (a) differing levels of student selectiveness; (b) differing evaluation philosophies and systems; and (c) differing quality and rigor of the curriculum. Saracki (1982) suggests using a weighted undergraduate grade point average to eliminate some of these confounding variables. Both the cumulative and science GPA utilized for this study were "raw" undergraduate GPAs, and thus may have been influenced by these variables. The small sample size used in this study must also be considered in the interpretation of the results.

In contrast to the findings in the present study regarding non-correlation of CGPA and SGPA and graduation rates, higher CGPA and SGPA were found to be related to higher quartile rankings. Students in the upper graduation quartiles tended to have higher undergraduate CGPA and SGPA. These results suggest that, in terms of medical school academic achievement, the skills and competencies which are measured by CGPA and SGPA are useful differentiating predictors. These predictors may be useful for faculty as they identify students who would benefit from academic and/or personal support measures. Students who enter medical school with lower undergraduate cumulative and science GPAs may benefit from participating in academic and personal support opportunities, particularly given the competitive nature of some medical specialty areas.

Personality Factors Relationship to Performance and Rankings

It was hypothesized that the personality traits as measured by the $16 \mathrm{PF}$ Questionnaire $5^{\text {th }}$ ed. were related to graduation rates and academic performance quartile 
rankings (Clap \& Reid, 1976; Cariaga-Lo et al., 1997; Ferguson et al., 2003; Green et al., 1991; Hall \& Bailey, 1992; Lievens et al., 2002; Nath, 1987; Peng et al., 1995; Shen \& Comrey, 1997; Webb et al., 1997). The findings of this present study suggest that both the Global and Primary factors of the $16 \mathrm{PF}$ have mixed results relative to the hypothesis. The low sample size of the non-graduating group further confounds the study. Given this small N, the results for Research Question 3 should be considered exploratory and interpreted with caution.

The findings suggest that lower levels of Anxiety, and higher levels of Extraversion and Independence, are related to higher graduation rates. These findings are similar to those suggested by Nath (1978) who found that lower levels of Anxiety, and higher levels of Independence were associated with higher levels of academic performance. The findings regarding Extraversion contradict findings reported by Lievens (2000, 2002), Peng and colleagues (1995), and Tutton (1996), although this latter study used the California Personality Inventory rather than the 16PF.

Students with higher levels of Extraversion tend to be relationship-seeking, gregarious and may perform better in cooperative learning environments. They may be perceived as warm, lively, bold, and may be better at consensus building and problemsolving in groups (Cattell \& Schuerger, 2003). These qualities may be especially in group learning situations and as students perform clinical rotations and must interact with patients, families and a variety of health care professionals. 
Lower levels of Anxiety also appear to be related to higher graduation rates. Cattell (1997) suggests that lower levels of Anxiety are related to self confidence, emotional stability, and higher degrees of relaxation and inner calm. Medical students with these qualities may possess superior coping skills and higher levels of resiliency, and may better manage the inevitable anxiety and stressors associated with medical school. Students with extremely low levels of anxiety, however, may deny stress and under-react to, or under-estimate, stressors. In considering these findings, School of Medicine faculty may wish to consider identifying anxiety prone students, and designing academic and personal support interventions to decrease their anxiety levels. Counseling interventions which lower anxiety may well prove helpful in increasing graduation rates.

Students with higher levels of Independence (self determination) may have an advantage in medical school environments which demand and reward autonomous, self directed learning. Students with higher levels of independence tend to be persuasive and assertive, and they may be more apt to ask questions (Cattell \& Schuerger, 2001; Cattell, 1995). They may approach novel learning situations with greater confidence, possessing higher levels of self directedness. These qualities and behaviors may prove beneficial during both basic science and clinical years of training, particularly in learning or patient care environments which are ambiguous and/or high-pressured. Given these preliminary Global Factor results, academic and personal support interventions which are targeted at highly extraverted and anxious students and students who appear overly dependent on their peers and/or the faculty may be beneficial.

Although the findings regarding Self-Control and graduation rates were not significant, an inverse trend was evident. In other words, Students with lower levels of 
Self-Control appear to graduate at higher rates than their peers with less self-control. These counterintuitive findings are not supported in the literature. One might hypothesize, however that students with lower levels of Self-Control may be less perfectionistic and rigid and may approach novel learning environments with less anxiety.

The hypotheses regarding relationships between higher levels of Tough Mindedness and graduation rates was not supported. In other words, students who had higher levels of Tough Mindedness did not appear to graduate at higher rates. These findings were surprising given the literature's support of the relationships between academic achievement and tough mindedness (Shen \& Comrey, 1997) One might hypothesize that these findings may be related to a tendency for these students (and perhaps medical students in general) to exhibit higher than average cognitive levels and perfectionism tendencies.

In the present study, none of the Global Factors (Extraversion, Anxiety, Tough mindedness, Independence and Self Control) appeared to correlate with quartile ranking. The findings were unexpected considering the relationships found in this same study between three of these variables (Extraversion, Anxiety, and Independence) and graduation rates, described above., Quartile ranking and graduation rates were considered to be related in the development of the research questions for this study. Thus, it seemed likely that a dependent variable would similarly affect both outcome variables. A review of the literature does not shed light on how these three variables affect two seemingly related dependent variables in such different ways. One might hypothesize, however, that 
quartile rankings of medical students are arbitrary and that the homogeneity of this group makes the differentiation of personality traits difficult.

Another potential factor which may influence these results relates to the premise that medical students are "persistors." Typically, medical schools experience low attrition rates (as is evidenced in this study). These highly motivated students may compensate for deficiencies in the curriculum (Norman, 2002) and in themselves, thereby succeeding academically. This persistor tendency may operationalize in a way that overshadows or influences quartile ranking placement.

Five of the Primary Factors, Emotional Stability, Dominance, Liveliness, Social Boldness, and Apprehension, appeared to correlate with higher graduation rates. The first primary factor, Emotional Stability refers to ego strength and appears to be related to higher graduation rates. Shen and Comrey (1997) and Peng and colleagues (1995) report similar findings, relating Emotional Stability with academic achievement. Students with higher levels of emotional stability can be described as more mature, calmer, steady, persevering and more emotionally resilient than their lower ranking peers (Cattell \& Schuerger, 2001). They may have higher frustration tolerance and better problem solving skills, and they may be more able to delay gratification. Medical students with these skills/qualities may be more able to adapt to ambiguous, intellectually challenging, and high pressure learning and patient care environments.

Cattell (1995) suggests that higher levels of emotional stability also enables individuals to cope better with stressors, to modulate emotions, and to consider alternative viewpoints, interests and goals. Medical students with these skills may acknowledge and confront problems rather than procrastinate, and they may prepare 
better for negative events (i.e. regular exams, National Board Examinations, new or difficult medical procedures or interventions, etc.). They may plan ahead, developing effective study plans, mentally rehearsing procedures and presentations, and more effectively managing their time and priorities. Cattell (1989) further suggests that these individuals possess a higher degree of ego strength which enables them to be more helpful to others who are experiencing dangerous or uncomfortable situations (i.e. physicians).

The findings regarding Dominance in this study are similar to those reported by Ping and colleagues (1995). Students with higher levels of Dominance may potentially be more competitive, assertive, aggressive, socially bold, controlling, and persuasive, and as such, they may distinguish themselves in competitive learning environments. They may appear more self confident and competent (Karson et al., 1997). These students may potentially be more apt to identify, assert, and address their learning needs, more effectively utilizing support measures and resources, and thereby better compensating for interpersonal, cognitive and/or environmental deficiencies. As suggested previously, these students may persist in difficult learning environments in spite of these deficiencies. Students with extreme levels of Dominance may be impulsive or tend to act out in stressful environments. One might hypothesize that extreme levels of Dominance may be mediated by higher levels of Emotional Stability. School of Medicine Admission Committees may wish to consider Levels of Dominance in the students whom they interview. Students who are assertive and who demonstrate leadership experience may well experience higher levels of academic success than their counterparts. 
Medical students with higher levels of Liveliness also graduated at higher rates than their counterparts. Students with higher levels of Liveliness may approach academic and patient care responsibilities with more optimism, enthusiasm and energy; they may work at a faster pace than their peers and respond well to high levels of internal and external stimulation (Karson et al., 1997). These students may well be have a significant advantage, given the demands of medical school,

Medical students with higher levels of Liveliness may also be apt to possess a divergent thinking style (Cattell, 1995). They may be more skilled at brainstorming new ideas, generating new associations, engaging in novel problem solving tasks and processing information quickly (i.e. thinking on their feet).

Students with higher levels of Social Boldness also appear to graduate at higher levels than their counterparts. Medical students with higher levels of Social Boldness may be more apt to take risks, more able to integrate and respond to negative feedback and more resilient under stress. They may be drawn to novel challenging or stressful learning and patient care situations. Individuals with higher levels of Social Boldness may experience less physiologic reactivity to these situations (Aaron, 1999; Henderson \& Zimbardi, 2001). This hypothesized physiologic under-reactivity may be particularly helpful to medical students as they navigate more demanding, unpredictable, and stressful clinical situations. Cattell and Schuerger (2001) suggest that individuals with higher levels of Social Boldness may be drawn to high stress professions. Future research which examines the impact of Social Boldness on residency choice (i.e. emergency medicine), and on satisfaction or competency with various clinical specialties may add to the literature. 
An inverse relationship regarding the Apprehension factor and graduation rate was found; in other words, lower Apprehension levels correlated with higher graduation rates. Individuals with lower levels of Apprehension may be more self assured, secure, and self confident and may experience less guilt and self doubt than their more apprehensive counterparts (Cattell \& Schuerger, 2001; Cattell, 1995). One might hypothesize that these students can better manage the demands inherent in the medical school environment. They may appear more self assured, and they may inspire confidence in their peers and in the patients whom they treat. They may approach novel patient care responsibilities with less apprehension and self doubt, and as a result, experience better learning (and patient care) outcomes.

In the present study, an inverse relationship also was observed with the Self Reliance factor and graduation rates; that is, lower levels of self reliance appear to be related to higher graduation rates. This finding was surprising and appears to contradict other results of this study. Students with lower self reliance levels, however, may tend to be more group oriented and have higher affiliation needs. They may seek out help from others more readily. These tendencies may be especially helpful in the medical school environment (such as the one in this study), which increasingly requires and values cooperative learning experiences and teamwork.

Conclusions/Implications

Conclusions drawn from these results were made within the scope of the assumptions and limitations of the study. The present research suggests in a preliminary way that certain personality factors are associated with success in medical school. Three of the 16PF Global factors (Extraversion and Anxiety, and Independence) appear to be 
related to higher graduation rates. Five of the 16PF Primary factors (Emotional Stability, Dominance, Liveliness, Social Boldness, and Apprehension) also appeared to be related to higher graduation rates. Demographic factors (race, gender, age) did not appear to be related to higher graduation rates. Higher CGPA, SGPA, and cumulative MCAT score also were not related to higher graduation rates, and in fact, higher MCAT composite scores appeared to be inversely correlated with lower graduation rates.

A review of the literature suggests that that these cognitive factors have become the gold standard used by admission committees to predict performance in medical school (Kulatunga-Moruzi \& Norman, 2002). Given these preliminary findings and the high value schools of medicine typically place on cognitive factors (higher CGPA, SGPA, and cumulative MCAT) as predictors of success in medical school, further study of these variables is warranted. Additionally, admission committees who use these factors as the sole criteria for determining admission status may wish to augment their process with the consideration of other noncognitive factors. Strategies for assessing personality characteristics in the interview process should be investigated (i.e. personal statements, interview).

The lack of findings regarding sex and academic success are noteworthy and may suggest a more even playing field in the basic and clinic environments. Efforts in the last decade to increase access to mentors, supports, to diversify the faculty and to create more supportive learning environments may be having the intended effect on women students.

The findings from this study regarding personality factors and performance in medical school, while preliminary in nature, may inform pre-med advising efforts, 
admission procedures, and interventions designed to identify and retain at risk medical students. These finding may be especially critical for nontraditional students and all students who enter with lower incoming CGPA \& SGPA who wish to apply for more selective residencies.

Recommendations for Future Study:

The following recommendations are provided, based on the results of this study:

1. Future research should be conducted using a larger, broader sample of medical students to increase the generalizability of findings. A sample which relies on students from less rural populations may yield significantly different results.

2. Future research should be undertaken which more fully considers the implications of social economic status, family of origin, rural vs. urban status, and stressors/life events.

3. Future research should be conducted which examines how the demographic, cognitive and personality factors used in the study impact the basic science verses the clinical years of medical education.

Limitations of Findings: 
Conclusions suggested from these findings were made within the scope of the assumptions and limitations of the study. In interpreting the results, the following limitations should be considered:

1. The number of students who did not graduate from medical school was smaller than anticipated, making comparisons between the graduated and not-graduated groups preliminary at best.

2. Participants were generally from a rural geography, and as such are not likely representative of other medical students from non-rural areas of the United States or other countries.

3. Academic quartile ranking and graduation rates used in this study were derived at the end of the participant's medical careers and thus may not have been sensitive to differences in the basic sciences and clinical years. 


\section{REFERENCES}

Aaron.E. N. (1999). High Sensitivity as one source of fearfulness and shyness: Preliminary research and clinical implications. In L. A. Schmidt \& J. Schulkin clinical outcomes. Series in affective sciences (pp. 251-272). New York: Oxford University Press.

American Medical Association (2003). Medical School Admissions (n.d.). Retrieved December 15, 2003, from http:/www.aamc.org/

Association of American Medical Colleges. (2002). Medical school requirements United States and Canada 2003-2004. United States.

Association of American Medical Colleges. (2003). Medical school requirements United States and Canada 2003-2004. United States.

Bolton, B. (1979). The Tennessee self-concept scale and the normal personality sphere (16PF). Journal of Personality Assessment, 43(6), 608-613.

Borges, N. J., \& Osmon, W. R. (2001). Personality and medical specialty choice: Technique orientation versus person orientation. Journal of Vocational Behavior, $58,22-35$.

Borges, N. J., \& Savickas, M. L. (2002). Personality and medical specialty choice: A literature review integration. Journal of Career Assessment, 10(3), 362-380.

Brooke, D., Edwards, G., \& Taylor, C. (1991). Addiction as an occupational hazard: 144 doctors with drug and alcohol problems. British Journal of Addiction, 86, 1011-1 016. 
Cariaga-Lo, L. D., Enarson, C. E., Crandall, S. J., Zaccaro, D. J., \& Richards, B. F. (1997). Cognitive and noncognitive predictors of academic difficulty and attrition. Academic Medicine, 72(10), S69-S71.

Cariaga-Lo, L. D., Richard, B. E., Hollingsworth, M. A., \& Camp, D. L. (1996). Noncognitive characteristics of medical students: Entry to problem-based and lecturebased curricula. Medical Education, 30, 179-186.

Carmel, S., \& Bernstein, J. (1987). Perceptions of medical school stressors: Their relationship to age, year of study and trait anxiety. Journal of Human Stress, 13(1), 39-44.

Cattell, H. B. (1989). The 16PF: The personality in Depth. Champaign, IL: Institute for Personality and Ability Testing.

Cattell, H. E. P., \& Schuerger. (2001). Essentials of 16PF Assessment. Champaign IL: John Wiley and Sons Inc.

Cattell, R. B., Cattell, A. K., \& Cattell, H. E. (1993). Sixteen Personality Factor Questionnaire. Champaign, IL: Institute of Personality and Ability Testing, $5^{\text {th }}$ ed.

Cattell, R. B., \& Cattell, H. E. P. (1995). Personality structure and the new fifth edition of the 16PF. Educational and Psychological Measurement, 55(6), 926-937.

Chan-Ob, T. \&, Boonyanaruthee, V. (1999). Medical student selection: Which matriculation scores and personality factors are important? Journal of the Medical Association of Thailand, 82(6), 604-10.

Claap, T. T., \& Reid, J. C. (1976). Institutional selectivity as a predictor of applicant selection and success in medical school. Journal of Medical Education, 51(10), $850-852$ 
Coleman D. (1995) Emotional Intelligence and Advantage? An Exploration of the Impact of Emotional and General Intelligence on Individual Performance. New York: Bantam Books, 1995

Conn, S. R., \& Rieke, M. L. (1994). The 16 PF Fifth Edition technical manual. Champaign IL: Institute for Personality and Ability Testing Inc.

Daugherty, S. R., Eckenfels, E. J., \& Schmidt, J. L. (1990). Longitudinal analysis of admission decision: Admission committee dissent as a predictor of problems in medical school. Academic Medicine, 65(9), S1-S2.

Dorr, D. (1981). MMPI profiles of emotionally impaired physicians. Journal of Clinical Psychology, 37(2), 451-455.

Elam, C. L. (2004). Use of "emotional intelligence" as one measure of medical school applicants' noncognitive characteristics. Academic Medicine, 75, 445-446.

Edwards, J. C., Johnson, E. K., \& Molidor, J. B. (1990). The interview in the admission process. Academic Medicine, 65, 167-177.

Engler, B. (1979). Personality Theories: An Introduction. Boston: Houghton Mifflin Co.

Fadem, B., Schuchman, M., \& Simring, S. S. (1995). The relationship between parental income and academic performance of medical students. Academic Medicine, 70(12), 1142-4.

Feil, D., Kristian, M. \& Mitchell, N. (1998). Older medical students' performances at McGill University. Academic Medicine, 73(1), 98-100.

Ferguson, E., James, D., O’Hehir, F., \& Sanders, A. (2003). Pilot study of the roles of personality, references, and personal statements in relation to performance over the five years of a medical degree. British Medical Journal, 326(7386), 429-32. 
Ferguson, E., Sanders, A., O’Hehir, F., \& James, D. (2000). Predictive validity of personal statements and the role of the five-factor model of personality in relation to medical training. Journal of Occupational and Organizational Psychology, 73, 321-344.

Firth-Cozens, J. (1997). Depression in doctors. In: M.M. Robertson \& E. Kantona, (Eds.), Depression and Physical Illness, pp. 95-111. New York: John Wiley.

Fitzpatrick, K. M., \& Wright, M. P. (1995). Gender differences in medical school attrition rates, 1973-1992, Journal of the American Medical Association, 50(6), 204-6.

Flaherty, J. A., \& Richman, J. A. (1993). Substance use and addiction among medical students, residents, and physicians. Psychiatric Clinic of North America, 16, 189197.

Friedman, C. P., \& Slatt, L. M. (1988). New results relating the Myers-Briggs Type Indicator and medical specialty choice. Journal of Medical Education, 63(4), 325327.

Gough, H. G. (1971). Scoring high on an index of social maturity. Journal of Abnormal Psychology, 77(3), 236-241

Gough, H. G. (1978). Some predictive implications of premedical scientific competence and preferences. Journal of Medical Education, 53, 291.

Green, A., Peters, T. J., \& Webster, D. J. T. (1991). An assessment of academic performance and personality. Medical Education, 25, 343-348.

Green, A., Peters, T. J., \& Webster, D. J. T. (1993). Preclinical progress in relation to personality and academic profiles. Medical Education, 27, 137-142. 
Haist, S. A., Wilson, J. F., Elam, C. L., Blue, A. V., \& Fossum, S. E., (2000), The effect of gender and age on medical school performance: Important interaction.. Advanced Health Science Education Theory and Practice. (3):197-205.

Hall, F. R., \& Bailey, B. A. (1992). Correlating students' undergraduate science GPAs, their MCAT scores, and the academic caliber of their undergraduate colleges with their first-year academic performances across five classes at Dartmouth Medical School. Academic Medicine, 67(2), 121-3.

Hall, F. R., Mikesell, C., Cranston, P., Julian, E., \& Elam, C. (2001). Longitudinal trends in the applicant pool for U.S. medical schools, 1974-1999. Academic Medicine, 76(8), 829-34.

Henning, K., E., S., \& Shaw, D. (1998). Perfectionism, the impostor phenomenon and psychological adjustment in medical, dental, nursing, and pharmacy students. Medical Education, 32(5), 456.

Henderson L., \& Zimbardo, P. G. (2001). Shyness as a clinical condition: The Stanford Model. In W.R., Crozier \& L.E.Alden (eds). International handbook of social anxiety: Concepts, research and interventions relating to the self and shyness (pp. 431-447). New York: Wiley.

Hobfell, S., E., Anson, O., \& Anonovsky A. (1982). Personality factors as predictors of medical student performance. Medical Education, 16(4), 251-258.

Hodgeson, C. S., \& Silver, B. (1997). Evaluating GPAs and MCAT scores as preditors of NBME! And clerkship performances based on student's data from one undergraduate institution. Academy of Medicine. 72(5): 394-396. 
Hojat, M., Robeson, M., Damjanov, I., Veloski, J. J., Glaser, K., \& Gonella, J. S. (1993). Students' psychosocial characteristics as predictors of academic performance in medical school. Academic Medicine, 68, 635-637.

Huffcutt A. I., \& Arthur W. (1996). A meta-analytic investigation of cognitive ability in employment interview evaluations: Moderating characteristics and implications for incremental validity. Journal of Applied Psychology. 81, 459.

Huxam, G. J., Lipton, A., Hamilton, D., \& Chant, D. (1989). What 'makes' a good doctor? Medical Education, 23, 3-13.

Inui, T. S., Williams, W. T., \& Goode, L. (1998). Sustaining the development of primary care in academic medicine. Academic Medicine, 73, 245.

Johnson, E. K., \& Edwards, J. C. (1991). Current practices in admission interviews at U.S. medical schools. Academic Medicine, 66(7), 408-412.

Jones, R.F., \& Adams, L.N. (1983). The relationship between MCAT science scores and undergraduate science GPA. Journal of Medical Education, 58(11), 908-911.

Jones, R.F., \& Thomas-Forques, M. (1984). Validity of the MCAT in predicting performance in the first two years of medical school. Journal of Medical Education, 59(6), 455-464.

Karson, M., Karson, S., \& O’Dell, J. (1997). 16 PF interpretation in clinical practice: A guide to the $5^{\text {th }}$ edition. Champaign, IL. Institute for Personality and Ability Testing.

Koenig, J. A., Sireci, S. G., \& Wiley, A. (1998). Evaluating the predictive validity of MCAT scores across diverse applicant groups. Academic Medicine, 73(10), 10951106. 
Kulatunga-Moruzi, C., \& Norman, G. R. (2002a). Validity of admissions measures in predicting performance outcomes: The contribution of cognitive and noncognitive dimensions. Teaching and Learning in Medicine, 14(1), 34-42.

Kulatunga-Moruzi, C., \& Norman, G. R. (2002b). Validity of admissions measures in predicting performance outcomes: A comparison of those who were and were not accepted at McMaster. Teaching and Learning in Medicine, 14(1), 43-48.

Lam, L., \& Kirby, S. L. (2002). Emotional intelligence and advantage? An exploration of the impact of emotional and general intelligence on individual performance. The Journal of Social Psychology, 142(1), 133-143.

Lee, J., \& Graham, A. V. (2001). Students' perception of medical school stress and their evaluation of a wellness elective. Medical Education, 35, 652-659.

Leonardson, G. R., Cook, S. W., \& Charboneau, G. (1987). The relationship between premedical school academic factors and actual medical school performance. South Dakota Journal of Medicine, 40(4), 21-26.

Lievens, F., Coetsier, P., De- Fruyt, F., \& De Maeseneer, J. (2002). Medical students' personality characteristics and academic performance: A five-factor model perspective. Medical Education, 36, 1050-1056.

Lindeman, S., Laara, E., Hakko, H., \& Lonnquist, J. (1996). A systematic review on gender-specific suicide mortality in medical doctors. British Journal of Psychiatry, 168, 274-279.

Lipton, A., Huxam, G. J., \& Hamilton, D. (1984). Predictors of success in a cohort of medical students. Medical Education, 18, 203-210. 
McGaghie, W. C. (1990). Qualitative variables in medical school admission. Academic Medicine, 65, 145-149.

McKegney, C. P. (1989). Medical education: A neglectful and abusive family system. Family Medicine, 21(6), 452-457.

Meit, S., Meit, H. T., \& Yasek, V. (1999). Personality traits of incoming WVU medical students: Phase I gender findings. The West Virginia Medical Journal, 95(3), 123126.

Meit. S., Borges, N., Cubic,B, \& Yasek,V. (in submission). The self-examined and the self imagined: A comparison of objective and subjective indices among incoming medical students.

Mitchell, K. J. (1990). Traditional predictors of performance in medical school. Academic Medicine, 65, 149-158.

Mitchell, K. J., Haynes, R., \& Koenig, J. (1994). Assessing the validity of the updated medical college admission test. Academic Medicine, 69, 393-401.

Montague, W., \& Odds, F. C. (1990). Academic selection criteria and subsequent performance. Medical Education, 24(2), 151-157.

Murden, R., Galloway, G. M., Reid, J. C., \& Colwill, J. M. (1978). Academic and personal predictors of clinical success in medical school. Journal of Medical Education, 53(9), 711-719.

Nath, L. M. (1987). Role of personality and interest for students' success in medical course. Academic Medicine, 65, 145-149.

Norman G. (2003). Research in medical education. British Medical Journal, 324, 15601562. 
Nowacek, G.A., Pullen, E., Short, J., \& Blumner, H. N. (1987). Validity of MCAT scores as predictors of preclinical grades and NBME part I examination scores. Journal of Medical Education, 62(12), 989-991.

Peng, R., Khaw, H. H., \& Edariah, A. B. (1995). Personality and performance of preclinical medical students. Medical Education, 29, 283-288.

Powis, D. A. (1994). Selecting medical students. Medical Education, 28, 443-469.

Ramsbottom-Lucier, M., Johnson, M. M., \& Elam, C. L. (1995). Age and gender differences in students' preadmission qualifications and medical school performances. Academic Medicine, 70(3), 236-239.

Reede, J. Y. (1999). Predictors of success in medicine. Clinical Orthopaedics and Related Research, 362, 72-7.

Richings, J. C., Khara, G. S., \& McDowell, M. (1986). Suicide in young doctors. British Journal of Psychiatry, 149, 475-478.

Robbins, L., Robbins, E. S., Katz, S. E., Gelibeter, B., \& Stern, M. (1983). Achievement motivation in medical students. Journal of Medical Education, 58(11), 850-858.

Rolfe, I. E., Pearson, S., Powis, D. A., \& Smith, A. J. (1995). Time for a review of admission to medical school? Lancet, 346(8986), 1329-1333.

Rosenfeld, L. M., Hojat, M., Veloski, J. J., Blacklow, R. S., \& Goepp, C. (1992). Delays in completing medical school: Predictors and outcomes. Teaching and Learning in Medicine, 4, 162-167.

Rosenthal, J. A. (2001). Statistics and data interpretation for the helping profession. Belmont, CA: Brooks/Cole. 
Russell, M., \& Carol, D. (1994). The 16PF 5th edition: Administrator's manual. Champaign, IL: Institute for Personality and Ability Testing.

Sade, R. M., Stroud, M. R., Levine, J. H., \& Fleming, G. A. (1985). Criteria for selection of future physicians. Annals of Surgery, 201(2), 225-230.

Salovey, P., \& Mayer, J. D. (1990). Emotional intelligence. Imagination, Cognition, and Personality, 9, 185-211.

Sarnacki, R. E. (1982). The predictive value of the premedical grade-point average. Journal of Medical Education, 57(3), 163-169.

Schofield, W. (1953). A study of medical students with the MMPI III: Personality and academic success. Journal of Applied Psychology, 37(1), 47-52.

Scott, C. S., Greig, L. M., Brock, D. M., Hunt, D. D., Shaad, D. C., \& Carline, J. D. (1988). Early identification of future medical students using initial undergraduate grades. Medical Education, 22(5), 389-392.

Shelldrake, P. (1975). How should we select? - A sociologist's view. British Journal of Medical Education, 9, 91.

Shen, H., \& Comrey, A. L. (1997). Predicting medical students' academic performances by their cognitive abilities and personality characteristics. Academic Medicine, 72(9), 781-786.

Simpson, K. H., \& Budd, K. (1996). Medical student attrition: a 10-year survey in one medical school. Medical Education, 30, 172-178.

Smith, S. R. (1998). Effect of undergraduate college major on performance in medical school. Academic Medicine, 73(9), 1006-1008.

Spooner, C. E. (1990). Help for the gatekeepers: comment and summation on the 
admission process. Academic Medicine, 65, 183.

Swanson, D. B., Ripkey, D. R., \& Case, S. M. (1996). Relationship between achievement in basic science coursework and performance on 1994 USMLE step 1. Academic Medicine, 71, S28-30.

Tekian, A. (1998). Attrition rates of underrepresented minority students at the University of Illinois at Chicago College of Medicine, 1993-1997. Academic Medicine, 73(3), 336-338.

Tekian, A., Mrtek, R., Syftestad, P., Foley, R., \& Sandlow, L. J. (1996). Baseline longitudinal data of undergraduate medical students at risk. Academic Medicine, $71(10), 86-87$.

Tutton, J. P. (1996). Psychometric test results associated with high achievement in basic science components of a medical curriculum. Academic Medicine, 71, 181-186.

Tutton, P., \& Price, M. (2002). Selection of medical students. British Medical Journal, 324(7374), 1170-1171.

Tyysen, R., Vaglum, P., Gronvold, N. T., \& Ekenberg, O. (2001). Factors in medical school that predict postgraduate mental health problems in need of treatment: A nationwide longitudinal study. Medical Education, 35, 110-120.

Tyssen, R., \& Vaglum, P. (2002). Mental health problems among young doctors: An updated review of prospective studies. Harvard Journal of Psychiatry, 10, 154165.

Van Susteren, T. J., Suter, E., Romrell, L. J., Lanier, L., \& Hatch, R. L. (1999). Do interviews really play an important role in the medical school selection decision? Teaching and Learning in Medicine, 11(2), 66-74. 
Veloski, J. J., Callahan, C. A., Xu, G., Hojat, M., \& Nash, D. B. (2000). Prediction of students' performances on licensing examinations using age, race, sex, undergraduate GPAs, and MCAT scores. Academic Medicine, 75(10), 28-30.

Webb, C. T., Sedlacek, W., Cohen, D., Shields, P., Gracely, E., Hawkins, M., \& Nieman, L. (1997). The impact of nonacademic variables on performance at two medical schools. Journal of the National Medical Association, 89(3), 173-180.

Weiss, M., Lotan, I., Kedar, H., \& Ben-Shakhar, G. (1988). Selecting candidates for a medical school: An evaluation of a selection model based on cognitive and personality predictors. Medical Education, 22(6), 492-497.

Wiley, A., \& Koenig, J. A. (1996). The validity of the medical college admission test for predicting performance in the first two years of medical school. Academic Medicine, 71(10), 83-85. 


\section{APPENDIX A \\ Definition of Terms}

For the purpose of this study the terms below are defined for the reader:

Medical students: persons enrolled or (previously enrolled) in a 4-year postbaccalaureate program in the School of Medicine at a mid-Atlantic university.

Academic Indice or Noncognitive predictors:

(1) Medical College Admission Test (MCAT). The MCAT is a national standardized exam taken by medical school applicants. The MCAT score used is the sum of the six subtest scores: biology, chemistry, physics, general science, reading comprehension, and quantitative skills.

(2) Undergraduate cumulative grade point average: the average of all science and nonscience courses.

(3) Undergraduate cumulative science grade point average: the average of all science courses. 


\section{APPENDIX B}

Personality characteristics examined as defined by the 16 Personality Factors

Questionnaire, $5^{\text {th }}$ edition are provided in Table A1

Table A1:

Factor

The continuum representing:

\begin{tabular}{|l|l|l|}
\hline Warmth & A & $\begin{array}{l}\text { Reserved, impersonal style, distance vs. warmth, attentive } \\
\text { towards others, outgoing }\end{array}$ \\
\hline Reasoning & B & Concrete vs. abstract \\
\hline $\begin{array}{l}\text { Emotional } \\
\text { stability }\end{array}$ & C & $\begin{array}{l}\text { Emotionality, reactivity, emotionally changeable vs. } \\
\text { emotionally stable, mature, adaptive }\end{array}$ \\
\hline Dominance & E & $\begin{array}{l}\text { Cooperative, deferential, avoidance of conflict vs. } \\
\text { dominant assertive, forceful. }\end{array}$ \\
\hline Liveliness & F & $\begin{array}{l}\text { Restrained, serious, careful vs. lively animates } \\
\text { spontaneous. }\end{array}$ \\
\hline $\begin{array}{l}\text { Rule } \\
\text { Conscious }\end{array}$ & G & Expedient, nonconforming vs. rule conscious, dutiful \\
\hline $\begin{array}{l}\text { Social } \\
\text { Boldness }\end{array}$ & H & $\begin{array}{l}\text { Shy, timid threat sensitive vs., socially bold, venturesome, } \\
\text { thick skinned }\end{array}$ \\
\hline Sensitivity & I & $\begin{array}{l}\text { Utilitarian, unsentimental, objective vs. sensitive, } \\
\text { aesthetic, sentimental }\end{array}$ \\
\hline Vigilance & L & $\begin{array}{l}\text { Trusting, unsuspecting, accepting vs. suspicious, wary, } \\
\text { vigilant, skeptical }\end{array}$ \\
\hline Abstractness & M & $\begin{array}{l}\text { Practical, grounded, solution oriented vs. imaginative, } \\
\text { abstracted (?), idea oriented }\end{array}$ \\
\hline Privateness & N & $\begin{array}{l}\text { Genuine, forthright, artless vs. discrete, private, } \\
\text { nondisclosing }\end{array}$ \\
\hline Apprehension & O & $\begin{array}{l}\text { Self-assured, unworried, complacent vs. apprehensive, } \\
\text { worried, self-doubting }\end{array}$ \\
\hline $\begin{array}{l}\text { Openness to } \\
\text { Change }\end{array}$ & Q1 & $\begin{array}{l}\text { Traditional, attached to the familiar vs. open to change, } \\
\text { experimenting }\end{array}$ \\
\hline Self-Reliance & Q2 & $\begin{array}{l}\text { Group oriented, affiliativeness Self-reliant, solitary, } \\
\text { individualistic }\end{array}$ \\
\hline Perfectionism & Q3 & $\begin{array}{l}\text { Tolerance for disorder, unexacting flexible vs. } \\
\text { perfectionist organized self-disciplined }\end{array}$ \\
\hline Tension & Q4 & $\begin{array}{l}\text { Relaxed, placid, patient vs. high energy, tense, driven, } \\
\text { impatient }\end{array}$ \\
\hline
\end{tabular}

